OPEN ACCESS

Edited by:

Fredrik Rosqvist,

Uppsala University, Sweden

Reviewed by:

Christopher Blesso,

University of Connecticut,

United States

Shunxing Rong,

University of Texas Southwestern

Medical Center, United States

*Correspondence:

Åke Nilsson

ake.nilsson@med.lu.se

†These authors have contributed equally to this work

Specialty section

This article was submitted to Nutrition and Metabolism,

a section of the journa

Frontiers in Nutrition

Received: 11 June 2021

Accepted: 19 July 2021

Published: 18 August 2021

Citation:

Nilsson Å, Duan R-D and Ohlsson L (2021) Digestion and Absorption of Milk Phospholipids in Newborns and

Adults. Front. Nutr. 8:724006.

doi: 10.3389/fnut.2021.724006

\section{Digestion and Absorption of Milk Phospholipids in Newborns and Adults}

\author{
Åke Nilsson ${ }^{1 * t}$, Rui-Dong Duan ${ }^{2 \dagger}$ and Lena Ohlsson ${ }^{3+}$ \\ ${ }^{1}$ Division of Medicine, Gastroenterology, Department of Clinical Sciences Lund, Lund University, Lund, Sweden, \\ ${ }^{2}$ Gastroenterology and Nutrition Laboratory, Division of Medicine, Department of Clinical Science, Lund University, Lund, \\ Sweden, ${ }^{3}$ Division of Medicine, Experimental Vascular Medicine, Department of Clinical Science, Lund University, Lund, \\ Sweden
}

Milk polar lipids provide choline, ethanolamine, and polyunsaturated fatty acids, which are needed for the growth and plasticity of the tissues in a suckling child. They may also inhibit cholesterol absorption by interacting with cholesterol during micelle formation. They may also have beneficial luminal, mucosal, and metabolic effects in both the neonate and the adult. The milk fat globule membrane contains large proportions of sphingomyelin (SM), phosphatidylcholine (PC), and phosphatidylethanolamine (PE), and some phosphatidylserine (PS), phosphatidylinositol (PI), and glycosphingolipids. Large-scale technical procedures are available for the enrichment of milk fat globule membrane (MFGM) in milk replacement formulations and food additives. Pancreatic phospholipase A2 (PLA2) and mucosal phospholipase B digest glycero-phospholipids in the adult. In the neonate, where these enzymes may be poorly expressed, pancreatic lipase-related protein 2 probably has a more important role. Mucosal alkaline SM-ase and ceramidase catalyze the digestion of SM in both the neonate and the adult. In the mucosa, the sphingosine is converted into sphingosine-1-phosphate, which is both an intermediate in the conversion to palmitic acid and a signaling molecule. This reaction sequence also generates ethanolamine. Here, we summarize the pathways by which digestion and absorption may be linked to the biological effects of milk polar lipids. In addition to the inhibition of cholesterol absorption and the generation of lipid signals in the gut, the utilization of absorbed choline and ethanolamine for mucosal and hepatic phospholipid synthesis and the acylation of absorbed lyso-PC with polyunsaturated fatty acids to chylomicron and mucosal phospholipids are important.

Keywords: ceramidase, milk, phosphatidylcholine, phosphatidylethanolamine, phospholipase, sphingomyelin, sphingomyelinase

\section{INTRODUCTION}

Polar lipids account for a small proportion of milk lipids. They are located mainly in the milk fat globule membrane (MFGM). With two of its three membrane layers originating from the apical membrane of the mammary gland epithelial cells, the MFGM has features of the plasma membrane lipid composition (1). Phosphatidylcholine (PC), sphingomyelin (SM), diacyl- and plasmalogenic phosphatidylethanolamine (PE) are major polar lipids. In addition, MFGMs contain 
phosphatidylinositol (PI), phosphatidyl serine (PS), and glycosphingolipids. A major difference in phospholipid (PL) composition compared to commonly used milk replacement formulas is the high content of SM.

Milk fat globule membrane-enriched formulations may now be used in milk-replacement formulas and food additives. Potential health benefits may be related to choline, ethanolamine, and polyunsaturated fatty acid (PUFA) content effects in the gut mucosa (2), an inhibitory effect on cholesterol absorption, and an influence on the gut microbiome and immune function (3). Recent reviews have summarized the potential health effects of milk PLs (4), its effects in the gut of the neonate (5), and the enzymes involved in the digestion of choline PLs (6).

Here, we summarized the pathways for the digestion and absorption of milk polar lipids. We linked these pathways to the potential biological effects in the suckling neonate and the adult who ingests larger doses of MFGM lipids in dairy products. Our starting point was a long-term interest in the digestion and absorption of sphingolipids and other polar lipids and in chylomicron metabolism.

\section{COMPOSITION OF POLAR LIPIDS IN MILK}

\section{Polar Lipids in Milk}

Lipids in milk are first aggregated in droplets in the endoplasmic reticulum of lactating cells in a bleb or bud and then released in the alveolus lumen. During formation and secretion, the droplets fuse with each other and grow in size. At this stage, the droplets are enclosed in a single layer of membrane, and the main composition inside is triacylglycerols (TAG). At the surface of the lactating cells, these droplets are enveloped by two layers of plasma membrane and form the so-called milk fat globule membrane (MFGM). They are then secreted. The last two layers are enriched with PLs and sphingolipids. The polar lipids in the milk are, therefore, integral constituents of the globule membrane $(1,7)$.

Polar lipids account for about $1 \%$ of milk fat. The milk fat globules have a diameter ranging from 3 to $5 \mu \mathrm{m}$. In the MFGM, a variety of PLs, glycosphingolipids, and cholesterols associate with membrane proteins. The design and function of the MFGM, which is similar in humans and other mammals, is to stabilize the emulsion in the serum phase of milk and maintain permeability that facilitates digestion in the newborn. The composition of the PLs differs slightly among species. The total amount of PLs in the raw milk of a cow is $29.4-40 \mathrm{mg} / 100 \mathrm{~g}$ and in human milk, approximately $10-40 \mathrm{mg} / 100 \mathrm{~g}(4,8)$.

The predominant PLs in both human and bovine milk are SM, PC, and PE. PS and PI account for smaller fractions (9) (Table 1). PE, PI, and PS are enriched in the inner surface layer of the MFGM, whereas most of the PC, SM, and glycosphingolipids are located in the outer MFGM bilayer. The

Abbreviations: Alk-SMase, Alkaline sphingomyelinase; ARA, Arachidonic acid; BSSL, Bile salt-stimulated lipase; DHA, Docosahexaenoic acid; LA, Linoleic acid; N-CDase, Neutral ceramidase; PC, Phosphatidylcholine; PE, Phosphatidylethanolamine; PL, Phospholipid; SM, Sphingomyelin. fatty acid composition of SM is dominated by long and very longchain saturated fatty acids as 16:0, 22:0, the uncommon 23:0, and 24:0. Phosphatidylcholine contains a high concentration of saturated fatty acids and of oleic and linoleic acid. In human but not in bovine milk, PE is a source of arachidonic acid (ARA) and docosahexaenoic acid (DHA), $\alpha$-linolenic acid C18:3 can be found in small amounts in both human and bovine milk, with the content being influenced by diet (18). The acyl chains in human PLs are, thus, more unsaturated than in PLs of bovine milk. The PL content of bovine and human milk is compared in Table $\mathbf{1 .}$

The phospholipid content in human milk corresponds to a daily intake of $140 \mathrm{mg}$ in a 4 -week-old breastfed infant. The total choline intake is about $125 \mathrm{mg} /$ day. Water-soluble choline compounds such as glycerophosphocholine, choline phosphate, and free choline account for about $80 \%$ of the choline content in milk and SM and PC for about 20\% (19). Milk also contains water-soluble forms of ethanolamine. A recent review states that the concentration of ethanolamine in the blood and breast milk is $2 \mu \mathrm{M}$ (range of $0-12 \mu \mathrm{M}$ ) and approximately $46 \mu \mathrm{M}$, respectively (20). Some of the milk PE is plasmalogenic PE, and human milk is rich in ARA and DHA (21). The PI is rich in PUFAs but accounts for only a small fraction of the total inositol in milk.

\section{Polar Lipids in Dairy Products}

Dairy products vary in proportion between TAG and polar lipids. Butter, some cheeses, and cream are the most TAG rich, and their coproducts buttermilk and whey are relatively enriched in PL. The content of polar lipids in whole milk is about double the amount in skim milk. Lipids in buttermilk contain about $12 \%$ polar lipids, which can be more concentrated using ultrafiltration $(22,23)$. Butter serum is obtained after the melting and centrifugation of butter, and thus contains a slightly higher proportion of polar lipids than butter milk. Studies have shown the health effects of the intake of polar lipid-containing products; thus, the dairy industry has developed formulas even more enriched in such lipids (4).

\section{THE DIGESTION OF MFGM}

\section{Triacylglycerol Digestion}

The hydrolysis of milk TAGs in the suckling newborn depends mainly on the combined action of gastric lipase, the milk and pancreatic bile salt stimulated lipase (BSSL), and the pancreatic lipase-related protein 2 (PLRP 2), which are all expressed at birth (24). The digestion of TAGs is initiated in the stomach, where the MFGM becomes less stable at low $\mathrm{pH}$, pepsin digests protein in the membrane, and gastric lipase gets access to TAGs (24). This enzyme is specific for the Sn 3 position and hydrolyzes medium chain fatty acid esters faster than long-chain fatty acid esters (25). Gastric lipase was found to hydrolyze bovine milk PL-emulsified lipid droplets more effectively than soy lecithinemulsified lipid droplets with a similar size (26). In newborn pigs, lipid digestion and absorption were most effective with a formula using an MFGM-derived emulgator (27). Although the intestinal epithelium is differentiated, the digestive and absorptive capacity of the pancreas and small intestine is rapidly developing after birth, and the bile acid levels in the gut are lower than in the 
TABLE 1 | Amounts of phospholipids (PLs) in human and bovine milk (mg/100 ml).

\begin{tabular}{|c|c|c|c|c|}
\hline Phospholipids & Human $(\mathrm{mg} / 100 \mathrm{~mL})$ & $\%$ of total PL & Bovine (mg/100 mL) & $\%$ of total PL \\
\hline SM & $6.8-10.3$ & $28.5-43.3$ & $5.2-11.7$ & $4.0-29.5$ \\
\hline PE & $5.2-9.9$ & $21.8-41.6$ & $6.9-18.7$ & $23.2-72.2$ \\
\hline PC & $2.6-6.0$ & $10.9-25.2$ & $5.6-13.3$ & $8.0-46.4$ \\
\hline PS & $0.8-4.3$ & $3.4-18.0$ & $0.6-3.6$ & $3.4-24.5$ \\
\hline $\mathrm{Pl}$ & $0.7-4.0$ & $2.9-16.8$ & $1.2-3.6$ & $1.4-7.5$ \\
\hline
\end{tabular}

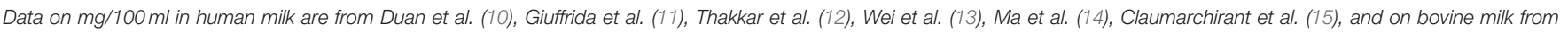
Pimentel et al. (16) and Graves et al. (17). Data on \% distribution in human milk are from Giuffrida et al. (11) and, in bovine milk, are from Anto and Warykas (4).

adult (28). The fatty acid absorption is incomplete (29). Although the average length of the small intestine is $275 \mathrm{~cm}$ at birth, i.e., half the average adult length, the tissue mass of the small intestine, the secretion of bile salts, and bile PC and the pancreatic secretory capacity expand rapidly after birth $(28,30)$. Although the development of the brain is the interest in focus for the in neonatal PL metabolism, the utilization of PUFAs and nitrogen bases in milk for expansion of the intestinal PL pools and hepatic PL traffic during maturation of the absorptive capacity must be large (28, 31-33).

Even in adults, the gastric lipase contributes to fat digestion. Emulsification of milk fat may enhance lipolysis and thereby cause an earlier peak in the post-prandial TAG level (34). In adults, duodenum and jejunum TAGs are effectively hydrolyzed through the concerted action of pancreatic colipase-dependent lipase (Lip-Col) and pancreatic BSSL. Lip-col acts effectively at an oil/water interphase where bile salts stabilize the colipase/lipase binding (35). It is a high-capacity enzyme that confers the ability to digest large fat-rich meals. The action of the enzyme on PC-stabilized TAG Emulsions in the presence of physiological bile salt concentration exhibits a delay but is enhanced through the initiation of PC hydrolysis by the secretory pancreatic phospholipase A2 IB (sPLA2 IB) (36). Lip-Col and sPLA2 IB interact effectively in the hydrolysis of milk fat globule TAGs (37). The enzymes that participate in TAG, glycero-PL, and SM-digestion are summarized in Figure 1.

\section{Glycerophospholipid Digestion}

As recently reviewed (6), the effective hydrolysis of the 2-ester bond of PC by sPLA2 IB is highly influenced by the bile salt/PL ratio. Although much of the $\mathrm{PC}$ hydrolysis by this enzyme coincides with TAG hydrolysis, part of the PC digestion is more extended. PL hydrolysis in a bile salt/PL/TAG emulsion occurs mainly in PL-rich bile salt/PL micelles that are formed as the TAG and PL hydrolyses proceed. As these micelles shrink in size due to the absorption of fatty acids and monoacylglycerols and the hydrolysis of some PLs, the sPLA2 activity against remaining $\mathrm{PC}$ declines with an increasing bile salt/PC ratio. We, therefore, believe that there are both pancreatic and mucosal phases of PC digestion that are mediated by the combined action of sPLA2 IB and PLB (6). The mucosal phospholipase B (PLB) (38), which is expressed in the mucosal brush border, particularly in the lower jejunum and ileum, hydrolyzes both ester bonds of PC even at high bile salt/PC ratios. This PLB is a protease-resistant and bile salt-dependent enzyme that may act throughout the whole lower part of the small intestine and must have an important role in the completion of the PC digestion [for ref see Nilsson and Duan (6)]. It acts both at the brush border and in the lumen. Studies on PLB knockout mice are, however, so far lacking. Even sPLA2 $\mathrm{X}$ is expressed in the mucosa and may have a role in the mucosal phase of PC digestion (39).

There is a lack of studies regarding the dietary effects of PC digestion. Pancreatic sPLA2 IB is a high-capacity enzyme; the activity of which depends on the interfacial properties of substrate and bile salt concentration. Furthermore, PLB has broad substrate specificity and hydrolyzes even glycerolipids and retinol esters. Dietary factors and the course of lipid digestion are, therefore, expected to influence the two enzymes differently. Interestingly, in a mouse, a fat-free vs. a fat-rich diet did not influence levels of pancreatic sPLA2 IB or mucosal PLB, but, when experimental chronic pancreatitis was developed, the decrease in sPLA2 IB was compensated for by an increase in PLB (40).

In vitro, phosphatidylethanolamine is hydrolyzed by PLA2 over a wide range of bile salt/PL ratios and a mix of PE and PC is more effectively hydrolyzed than is pure PC (41). Furthermore, PLRP2 has a higher activity against PE than against PC (42). In vivo, glycerophophorylethanolamine and ethanolamine are also formed in the lumen (43), and PLB is also active against PE (38). In vitro, human pancreatic PLA2 IB also hydrolyzes PI as effectively as PC and with the same biphasic influence of bile salts (44) (Figure 1).

The intestine also produces a sPLA2 IIA, which originates from the Paneth cells and does not attack PC but is active against PE, a dominant PL in gut bacteria (45). Since this enzyme is bactericidal, (46) it may have a dual function of preventing the utilization of ethanolamine by bacteria and recovering ethanolamine from dead bacteria and sloughed mucosal cells in the lower small intestine.

Of the milk phosphatidylethanolamine, some is plasmalogenic. Although PLA2 IB hydrolyzes the 2-ester bond, there is no hydrolysis of vinyl ethers in the gut lumen. The reacylation of acyl- and plasmalogenic lyso-PE into chylomicron $\mathrm{PE}$ is rather small. Plasmalogenic lyso-PE is degraded in the mucosa [for ref see Nilsson and Duan (6)] by the intracellular intestinal lysoplasmalogenase, which has been cloned and characterized, and which is found at its highest levels in the jejunum and upper ileum (47). 


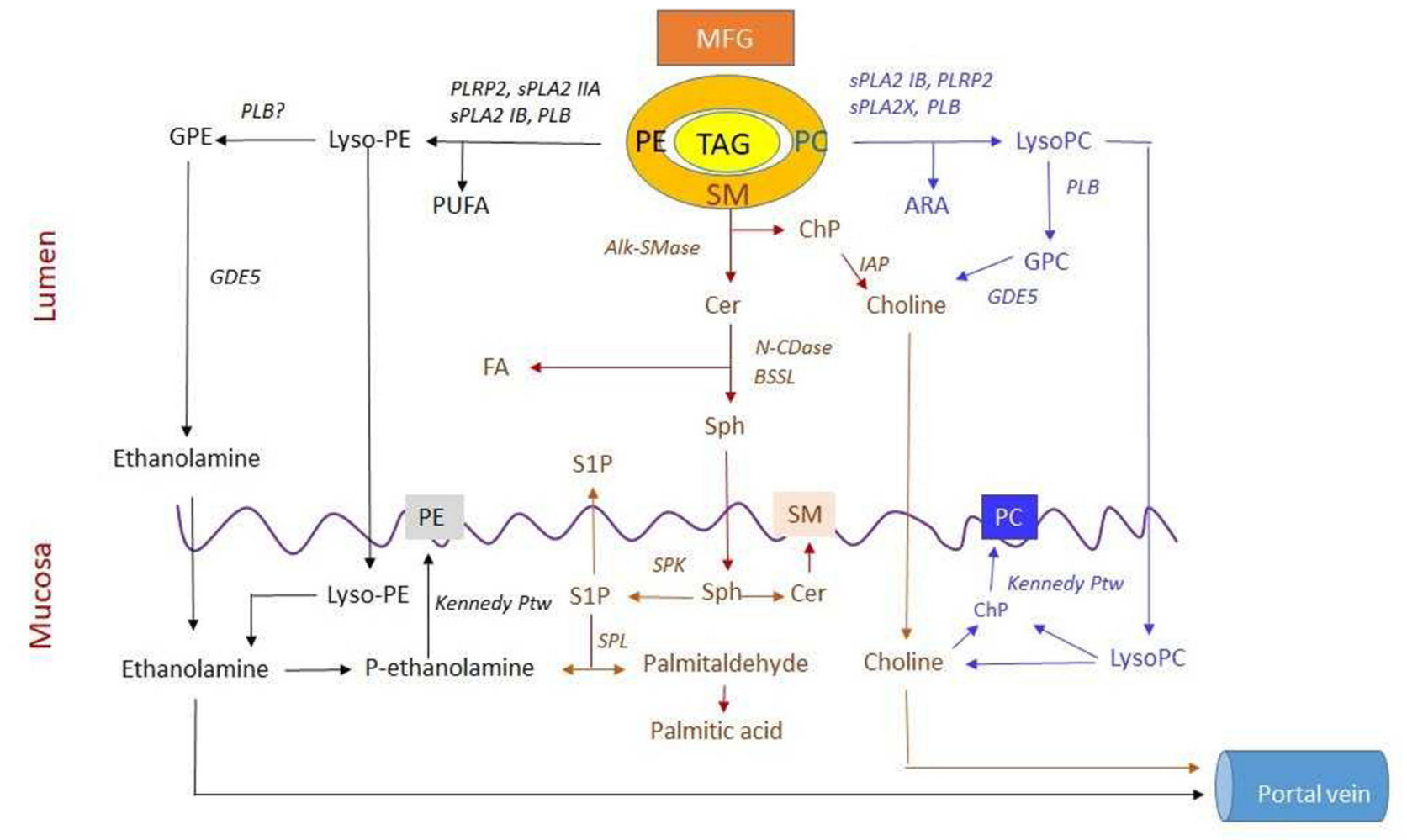

FIGURE 1 | Digestion and absorption of three major polar lipids in milk. Lipids in the milk are organized in the milk fat globule (MFG) with polar lipids in the membrane and triacylglycerol (TAG) in the core. The secretory pancreatic phospholipase A2 IB (SPLA2 IB), SPLA2, and SPLA2X hydrolyze phosphatidylcholine (PC) to lysoPC and may release arachidonic acid (ARA) for both phospholipid (PL) and prostaglandin (PGD) synthesis. Phospholipase B (PLB) can degrade both PC and lysoPC to glycerophosphocholine (GPC) and then by GDE5 to choline. Both lysoPC and choline are absorbed. Absorbed lysoPC may release choline that can, in turn, be phosphorylated to choline phosphate (ChP) in mucosal cells. Sphingomyelin (SM) is sequentially hydrolyzed by alkaline SMase (alk-SMase), neutral ceramidase ( $\mathrm{N}-\mathrm{CDase}$ ), and bile salt-stimulated lipase (BSSL) to ceramide (Cer), sphingosine (Sph), and fatty acid (FA). The cleaved ChP is degraded to choline by intestinal alkaline phosphatase (IAP). Then, Sph, choline, and FA are absorbed. The Sph in mucosa may be phosphorylated by sphingosine kinase (SPK) to S1P, most of which is degraded by sphingosine lyase (SPL) to palmitaldehyde and further converted into palmitic acid. This reaction generates ethanolamine phosphate (ethanolamine-P). Both ethanolamine and choline are substrate for synthesis of phosphatidylethanolamine (PE) and PC, respectively, via the Kennedy pathway or transported via portal vein. PE is degraded by sPLA2 IB, SPLA2 IIA, PLRP2, and PLB to lysoPE for absorption. LysoPE can be degraded by PLB to glycerophosphoethanolamine (GPE) and then to ethanolamine likely by GDE5 for absorption and resynthesis of PE. Meanwhile, polyunsaturated fatty acid (PUFA) can be formed during PE hydrolysis.

Furthermore, transport and metabolism of PUFA from PE, FA from SM, and ARA from PC hydrolysis are not shown in the figure (For other abbreviations, see the text).

In humans, sPLA2 $1 \mathrm{~B}$ is not expressed at birth (48). In human neonates, PLB is poorly studied; but, in rabbits, it is expressed post-weaning $(49,50)$. Additionally, in mice, PLB and sucrase-isomaltase, which is also expressed late, share similar enterocyte specific promoter structures (51). This speaks against a role in neonatal PC digestion in these species; yet meconium from humans contains both PLA2 activity and phospholipase activities, which hydrolyze PC to fatty acids and glycerophosphocholine $(52,53)$.

Thus, PLRP2, which is active against both PC and PE, may be essential for the milk glycero-PL hydrolysis in newborns (42). Furthermore, BSSL has broad substrate specificity. It has some activity against short-chain PC and lyso-PC under some in vitro conditions but is not active against long-chain PC and lyso-PC in the presence of physiological concentrations of bile salts (54) [for other ref see Nilsson and Duan (6)]. Since BSSL hydrolyzes lyso-PC in the absence of bile salts, the question on whether it may hydrolyze lyso-PC in neonates where bile salt levels are low is still relevant.

It is unknown when the expression of sPLA2 IB increases after birth. One might expect that it occurs when the bile acid pool expands and the bile PC secretion increases soon after birth, but data are lacking. Data on the course of digestion of glycero-PLs in newborns are scarce. When 11 duodenal contents from suckling infants, $<1$ month old, were analyzed for polar lipids, PE concentration was found to be very low in all samples. Lyso-PE dominated. The lyso-PC concentration exceeded the PC concentration, but a considerable amount of unhydrolyzed PC remained (55). These few data indicate that, even in the neonate, $\mathrm{PE}$ is rapidly digested in the proximal gut and PC digestion is more extended. 


\section{Sphingolipid Digestion -Enzymes Involved SMase}

SM is not hydrolyzed by any pancreatic enzymes but by sphingomyelinase (SMase), which cleaves the phosphocholine head group from SM and turns it into ceramide. Ceramide, in turn, is hydrolyzed by a ceramidase that cuts the acyl chain and turns ceramide into sphingosine for absorption. Based on the optimal pH, three types of SMases called acid, "neutral," and "alkaline SMases" have been identified. The key SMase responsible for digestion of SM in the gut is alkaline SMase (alk-SMase), which was discovered in the intestinal mucosa by Nilsson (56). Further studies show that it is attached to the surface of the intestinal brush border by a short intracellular domain with its active catalytic site exposed in the intestinal lumen (57). Alk-SMase shares no sequence similarities with either acid or neutral SMase but belongs to the ecto-nucleotide pyrophosphatase phosphodiesterase (eNPP) family (58). As a new member in the NPP family, alk-SMase is also called NPP7. Other enzymes in the NPP family hydrolyze nucleotides and nucleosides and are involved, e.g., in purinergic signaling, and autotaxin (NPP2) generates lysophosphatidic acid from lyso-PC and has important signaling functions related to inflammation, cell migration, and tumorigenesis $(59,60)$.

Although located on the surface of the brush border, alkSMase can be released into the intestinal lumen by bile salts and by trypsin, which cleaves the short intracellular domain of alk-SMase (61). Both the brush border-bound form and the released form are active, with the activity of the free form being higher than the mucosal form. The optimal $\mathrm{pH}$ of alk-SMase is approximately 9, but it becomes active at $\mathrm{pH} 6$ and above (62). A striking property of the enzyme is its resistance to pancreatic proteases. Its activity can be identified along the whole intestinal tract and in the stool (62). The activity in the fecal samples reflects the capacity of SM digestion of an individual. In alkSMase KO mice, SM in the intestinal content was increased 6 -fold and, in the feces, this increase was by $243 \%$; whereas ceramide in feces decreased by $74 \%$ (63). Alk-SMase is bile salt dependent. Taurocholate (TC) and taurochenodeoxycholate (TCDC) strongly enhance their activity at their critical micelle concentration (CMC) (57). In animals, alk-SMase activity is not found in the stomach, is very low in the duodenum, increasing in jejunum and ileum, and declining in the colon. The considerable alk-SMase activity was unexpectedly found in the hepatic bile of human beings, but not in the bile of any other mammalian species $(64,65)$. The bile alk-SMase is most likely localized on the surface of the canalicular membrane and released by bile salts into the bile. The secretion of alk-SMase in the human bile may endue humans with a higher capacity to digest dietary SM, and the digestion can start earlier in the duodenum.

Studies on fetal rats showed that the expression of alk-SMase sharply increased during day 20-23 of gestation (66). At this stage, the gut epithelium undergoes rapid differentiation with the formation of mature villus cells, distinct villus, and crypt structures soon before birth at day 23 of gestation. Studies on 3-week-old suckling pigs also showed high levels of alk-SMase in the jejunum and ileum (55). Furthermore, significant levels of alk-SMase were found in the meconium from both preterm and term human infants (67). Put together, the data indicate that nature endues the newborn mammals with the capacity to digest the SM in the breast milk after birth.

Alk-SMase can also cleave cholinephosphate from PC and lysoPC. The activity against PC is weak, about $2-8 \%$ of that against SM $(57,65)$. The activity against lysoPC is greater than against PC, but is still much lower than against SM. Differing from the activity against $\mathrm{SM}$, the optimal $\mathrm{pH}$ for alk-SMase to hydrolyze PC and lyso PC is 7.5. The formed cholinephosphate is a good substrate for intestinal alkaline phosphatase (68).

Acid and neutral SMase are two other SMases that hydrolyze $\mathrm{SM}$ to ceramide at different optimal pHs. There are two forms of acid SMase translated from the same gene SMPD1 but vary in glycosylation: One form is localized in the lysosomes intracellularly. The other form is secretable, and its activity can be identified in several body fluids, including the salivary and intestinal contents $(69,70)$. Acid SMase activity was found in milk, which hydrolyzes milk SM in vitro in the presence of bile salt (71), but no ceramide formation was seen in gastric contents from newborns (55). In addition, a relatively low activity of neutral SMase has been identified in the intestinal content, which is probably derived from the shedding of mucosal cells. The contribution of neutral SMases to milk SM hydrolysis is probably not significant because, differing from alk-SMase, they are rapidly inactivated by pancreatic enzymes in the intestinal tract (69). That is why, in alk-SMase KO mice, more than $90 \%$ of given SM accumulated in the gut (63).

\section{Neutral Ceramidase and Bile Salt-Stimulated Lipase}

In general, long-chain ceramides formed by SMase are poorly absorbed and are further hydrolyzed by neutral ceramidase $(\mathrm{N}$ CDase) to sphingosine and fatty acids, which are readily absorbed (72). The optimal $\mathrm{pH}$ of N-CDase is 7.6. This enzyme was purified from rat (73) and human (74) intestinal tracts. The amino acid sequence shows that the intestinal N-CDase is the product of the Asah 2 gene and has been previously cloned in the liver, kidney, and other tissues (75-77).

Similar to intestinal alk-SMase, the intestinal N-CDase is an ectoenzyme that is attached to the surface of the intestinal mucosa with a hydrophobic domain at its $\mathrm{N}$ terminal. The active site of the enzyme is exposed in the intestinal lumen, which facilitates its function to hydrolyze ceramide formed in the lumen by alk-SMase. N-CDase is also easily released from intestinal mucosa by bile salt. The activity of $\mathrm{N}$-CDase also requires the presence of bile salt. The levels of both enzymes are significantly decreased in bile-diverted rats (78). Similar to alk-SMase, NCDase is resistant to pancreatic proteases, such as trypsin and chymotrypsin. The enzyme can be transported along the whole gastrointestinal tract to the colon in active forms and can also be identified in the feces.

As mentioned, BSSL in milk and pancreatic juice have a key role in TAG digestion in both neonates and adults. In particular, BSSL was also found to hydrolyze the amide bond between sphingosine and fatty acids in ceramide (71). The activity is bile salt dependent, and the optimal $\mathrm{pH}$ is approximately 8.5. There is, however, little ceramide formation in the proximal gut 
where BSSL is most active. In addition, ceramide digestion was normal in BSSL KO mice (55) but was inhibited in N-CDase KO mice (79). Based on these findings, it can be concluded that $\mathrm{N}$ CDase is the most important enzyme in ceramide digestion in the intestinal tract.

\section{The Capacity of SM Digestion}

As summarized, (80) alk-SMase and N-CDase act mainly in the middle of the small intestine. The digestion of SM is more extended than that of TAG and is dose dependent. When up to 25-mg SM was given orally to rats, the course of digestion became more extended with an increasing dose (81). In ileostomy patients feeding up to $200-\mathrm{mg}$ milk SM in a test meal generated only modest increases of some ceramide and SM species in the content (82). A recent study on post-menopausal women who ingested cream cheese with 3- or 5-g milk polar lipids for 4 weeks found that the ceramide content in feces and ileostomy increased more than the content of milk SM species (83). The conclusion from these studies is that SM is extensively digested even with an MFGM lipid load, whereas ceramide digestion is more incomplete.

The course of digestion of SM in the neonate is unknown, although alk-SMase and N-CDase were found in the meconium of both preterm and term human infants (67). In duodenal content from babies $<1$ month old (55), no significant hydrolysis of SM to ceramide was observed. Thus, SM digestion is likely to be more extended than the PC and the PE digestion in the neonate. The digestion of SM has not been studied in newborn NPP7 KO mice, although these mice grow normally during suckling and exhibit a normal gross phenotype (63).

\section{Factors Affecting SM Digestion}

\section{Enzyme Levels in the Gut}

Many factors may affect the efficiency of milk SM digestion. Obviously, the level of alk-SMase is important since, in alkSMase KO mice, the major part of orally given radiolabeled SM was recovered in feces, and the appearance of radioactive SM fatty acid was reduced by $95 \%$ (63). A human study indicates that the level of alk-SMase is generally stable but may decrease somewhat above 45 years of age, indicating that the efficiency of SM digestion may decline in aged persons (84).

Dietary factors affect alk-SMase expression. The continuing increase of alk-SMase activity after birth in newborn rats indicates that $\mathrm{SM}$ in the milk may upregulate alk-SMase expression. Feeding adult ICR mice with SM for 22 weeks increased alk-SMase by $65 \%$ in the colon with increased enzyme protein and mRNA (85). Feeding rats with a water-soluble psyllium fiber for 4 weeks increased alk-SMase activity in the colon about 2-fold, whereas feeding high-fat diet decreased alkSMase activity by about 75\% (86). Insoluble fiber had no effect.

\section{Bile Salts in the Gut}

The activity of alk-SMase is bile salt dependent. All bile acids in the gut had some stimulatory effect on alk-SMase activity. The maximal effect occurs at their CMC. However, the stimulation by TC and TCDC, i.e., the taurine conjugates of the two primary bile acids, was 6- to 30-fold higher than the effect of glycine conjugates and of the secondary bile acid taurodeoxycholate (57). In human newborns, TC and TCDC are predominant bile acids. The mechanism for this type-specific activation of alk-SMase is not clear, but it is not due to a non-specific detergent action as non-physiological detergents, such as Triton X100 and CHAPS, did not stimulate but inhibit the TC and TCDC-induced activation of alk-SMase $(57,58)$. A specific interaction between the enzyme protein, the lipid substrate, and bile salts must be involved. In the case of N-CDase, TC and glycocholate stimulated the activity similarly. N-CDase is also activated by non-physiological detergents, such as Triton X100, which abolishes alk-SMase activity, indicating that different mechanisms are involved.

In line with the finding that bile salts release and activate alk-SMase and N-CDase activities, the alk-SMase activity was decreased by $85 \%$ in the intestinal lumen and by $68 \%$ in the feces of bile-diverted rats (78). Bile salt deficiency may thus reduce the efficiency of SM digestion, e.g., in cholestatic disorders and short bowel syndrome.

\section{Lipids in the Gut}

Digestion of SM is influenced by the presence of other lipids in the gut. In vitro studies with purified alk-SMase in the presence of bile salts showed that hydrolysis of SM is inhibited by other polar lipids, including PC, PE, and PI and lyso-PC (87). Moderate concentrations of long- and medium-chain free fatty acids stimulated the alk-SMase with lauric acid being most effective, whereas the inclusion of non-polar lipids as di- and triacylglycerols and cholesterol inhibited to a varying degree (88). Cholinephosphate was stimulatory (65). Even if alk-SMase is secreted in the bile in humans, one would thus expect that other lipids in the upper small intestine would delay the SM hydrolysis until after the peak of the TAG hydrolysis in the upper jejunum. Furthermore, the extended course of part of the PC hydrolysis and of the cholesterol absorption may influence the SM hydrolysis. The finalization of the PC hydrolysis by mucosal PLB and the hydrolysis of most of the SM by Alk-SMase may coincide in the jejunum and upper ileum (6). The SM digestion must be influenced by the course of digestion and absorption of other lipids, including other PLs and cholesterol.

\section{EFFECTS OF DAIRY POLAR LIPIDS ON CHOLESTEROL ABSORPTION}

\section{Mechanisms and Animal Studies}

Cholesterol is highly hydrophobic and dependent on micellar solubilization for absorption. Dietary and bile cholesterol is embedded in the mixed micelles formed by dietary lipids and the PC-rich bile. As lipolysis proceeds, the mixed micelles will contain free fatty acids, monoacyglycerols, and lyso-PC, as well. The course of both TAG and PC digestion will influence the absorption of cholesterol from such continuously changing mixed micelles $(89,90)$. The backbone sphingoid base of SM increases the polarity of SM and allows for stronger intermolecular hydrogen bonding between cholesterol and SM compared with other PLs $(91,92)$. The effect is mutual. Cholesterol slows down the rate of SM micellization with 
bile salts (93) and inhibits SM digestion (94). Cholesterol is transported across the enterocyte cell membrane by transmembrane-carrier proteins Niemann-Pick C1-like 1 (NPC1L1), CD36, and SR-BI, which are pivotal transporters that are located at the apical membrane of the small intestine (95). The cholesterol absorption is incomplete because cholesterol is also expelled from the mucosal cells by the ABCG5/G8 transporter (95).

After the initial observations that SM inhibits cholesterol absorption in vivo in rats (94), in lymphatic duct cannulated rats (96), and in Caco 2 cells (97), several animal studies have shown decreased cholesterol absorption after intake of milk SM $(98,99)$. In mice, milk SM and the products ceramide and sphingosine reduced plasma and liver lipids, including cholesterol (100).

Digestion of SM enhances cholesterol absorption since this was decreased in alk-SMase KO mice (101), indicating that the physical interaction between cholesterol and SM is essential for the inhibition of cholesterol absorption by SM. On the other hand, the generation of ceramide by alk-SMase increased the SM-induced inhibition of cholesterol absorption in the Caco 2 cell model. In this model system, the ceramide is not further digested (102). Long-chain ceramides and cholesterol have similar hydrophobicity. Both have low solubility in bile salt micelles without any other amphiphilic lipids. As fatty acids, monoacylglycerols, and polar lipids are absorbed, remaining ceramide and cholesterol may be poorly solubilized. This might explain why the absorption of the ceramide part of SM is more incomplete than the digestion of SM. Yet much of the ceramide is hydrolyzed in vivo, and the net effect of SM hydrolysis is expected to favor cholesterol absorption under most conditions.

A recent study finds that the NPC1L1 knockout and ezetimibe inhibit not only the absorption of cholesterol but also of the choline part of SM (103). It was assumed that the NPC1L1 transporter is an alternative pathway for SM absorption. Another possible explanation is that the inhibition of cholesterol absorption may increase luminal interactions between cholesterol and SM. Nevertheless, absorption of some intact SM and ceramides into the epithelial cell is possible since the absorption of SM in the alk-SMase KO mice is, although significantly decreased, not zero. After feeding radiolabeled ceramide or SM, a small proportion was found as ceramide in chyle (72) and specific milk SM ceramide species were found in chyle after feeding milk SM. Interestingly, this amount was increased when other polar milk lipids in addition to SM were included (104). The hydrolysis of glycero-PLs and other glycerolipids is necessary for the effective absorption of cholesterol and fat soluble vitamins via NPC1L1, CD36, and SRB1 (105). Although glycero-PLs may inhibit SM and ceramide digestion as described above, the digestion of these lipids might also enhance the uptake of intact SM and/or ceramide. The effect of different lipid vehicles on sphingolipid digestion and absorption needs to be further studied in vivo.

\section{Human Studies}

Human studies indicate that MFGM-rich products reduce cholesterol absorption, although results vary. Conway et al. (106) found that buttermilk consumption decreased cholesterol absorption and lowered plasma cholesterol. On the other hand, Ramprasath et al. (107) found no effect on cholesterol absorption, metabolism, or plasma lipoproteins with the ingestion of 1g milk SM per day for 2 weeks, and Keller et al. found some cholesterol-lowering effect but no beneficial change in the HDL/LDL cholesterol ratio when effects of 3- and 6-g milk polar lipids per day were studied over a 10-day period (108).

On one hand, a single dose of $1 \mathrm{~g}$ of milk polar lipids given to healthy individuals had little to no effect on post-prandial plasma lipids (109). On the other, a comprehensive study on post-menopausal women and subjects with ileostomy showed a reduced level of post-prandial TG-rich lipoproteins after a 4week daily intake of 5-g dairy-PL in the form of cream cheese (98). The same study also demonstrated that milk PL decreased the incorporation of dietary cholesterol into chylomicrons. In ileostomy subjects, both cholesterol and SM were increased in the ileal fraction after intake of milk PL. In a second study, it was concluded that the 4 -week milk PL supplementation (both 3 and $5 \mathrm{~g}$ ) decreased post-prandial total cholesterol, apoB/apoA1 ratio, total chylomicron SM and ceramide, and also the levels of potentially atherogenic SM and ceramide species (83).

\section{POSTABSORPTIVE METABOLIC PATHWAYS}

\section{The Fate of Lyso-PC and Choline in the Mucosa}

The gut epithelium contains high levels of sphingolipids, PC, $\mathrm{PE}$, and plasmalogenic PE. In particular, PC is needed for an effective secretion of chylomicrons [for ref see $(6,110,111)]$ and for the secretion of surfactant in the small intestine, which is rich in saturated PC species (112). Fat intake per body weight in newborns $(2.5-3.5 \mathrm{~g} / \mathrm{kg} /$ day $)$ is three to five times higher than in adults. A considerable amount of PC is needed for the secretion of chyle lipoproteins. However, data on the PL content in chyle chylomicrons of the human neonate are lacking. In 2week-old suckling rats, the PL/TAG ratio was about 6-fold higher in chylomicrons and manifold higher in total chyle lipoproteins than in rat milk (113).

Reacylation into chylomicron PC of absorbed lyso-PC formed by the action of PLA2 IB on dietary and bile PC increases with the dose of ingested fat (114). In adult humans, the amount of PC secreted in the bile significantly exceeds the amount of ingested PC [for ref see Nilsson and Duan (6)]. However, quantitative data on bile PC secretion in suckling human neonates are difficult to find. In mice, the hepatic $\mathrm{ABCB} 4$ transporter that mediates the transfer of PC into the bile is expressed just at the time of birth (115). The PL concentration in the bile in 2-week-old suckling rats was as high as $11.8 \mathrm{mM}$, and the ratio of $\mathrm{PL} /$ bile salts was similar to that in adult rats (113).

Different fatty acids are asymmetrically distributed between TAG and PLs in chyle, with the PUFAs and saturated fatty acids being overrepresented at the 2- and 1-position of the PLs. After feeding labeled ARA or linoleic acid in cream to lymphatic ductcannulated rats, both the radiolabels and the masses of these two PUFAs were higher in PLs than in TAG (116). The retention of 
${ }^{3} \mathrm{H}$-ARA in mucosal PLs was high (about $25 \%$ after $4 \mathrm{~h}$ ). ${ }^{3} \mathrm{H}$-ARA retention in mucosal PE and PI was severalfold higher than that of ${ }^{14} \mathrm{C}$-LA (117). Selective use for PL formation in the absorptive mucosa is thus a major pathway for absorbed ARA, whether it comes from milk PE or TAG, other dietary sources, or bile PC (118).

Among the enzymes that mediate the selective reacylation of lyso-PLs (119), the gut lyso-PC acyltransferase 3 (LPCAT 3 ) is crucial to the acylation of ARA and other PUFAs into mucosal and chylomicron PC. In mice, the genetic deletion of this enzyme results in lipid accumulation in the mucosal cells and malnutrition $(110,111,120)$. Oral administration of PC and olive oil allowed the LPCAT3 KO mice to survive, but the KO mice had shorter and wider smallintestinal villi and a larger small intestine. Plasma membranes of the enterocytes from LPCAT3-deficient mice also had reduced levels of NPC1L1, CD36, and FATP4, i.e., proteins that regulate lipid acid uptake, and a reduced ARA level in brush border PLs. The uptake of lipids by the small intestine was reduced.

During fat absorption, PC synthesis in the mucosa increases. Kennelly et al. (121) found that the selective intestinal deletion of CTP-phosphocholine cytidyltransferase $\alpha$ (CCT- $\alpha)$, the isoform of CCT that catalyzes the major regulatory step in the de novo synthesis of PC, decreased mucosal PC content but did not influence chylomicron formation. When a high-fat diet was used, however, a decreased uptake of fatty acids was observed. There was a compensatory increase of bile PC, related to a more proximal absorption of bile acids and increased enterohepatic bile acid secretion. Mucosal PC synthesis has such important metabolic implications.

The gut intestinal epithelium also secretes highly saturated molecular species of PC into the gut lumen (122), analogous to the secretion of lung surfactant. The quantity is difficult to estimate, and it is unknown whether the acylation of lyso-PC with a saturated fatty acid contributes to this secretion [for ref see Nilsson and Duan (6)].

The bacterial generation of trimethylamine and the subsequent generation of potentially harmful trimethylamineoxide from choline in the gut has received great attention (123). As recently demonstrated (124) and summarized (6), the rapid absorption of generated lyso-PC and the effective digestion by PLB may lead to less trimethylamine formation from choline in PC than from larger doses of orally given free choline.

In conclusion, mucosal reacylation reactions and de novo synthesis of PC are essential for normal lipid absorption and chylomicron formation. During suckling, the milk PC and SM contribute to these pathways, but other choline compounds in milk and bile PC are major contributors. Free choline transported by the portal vein is extensively used for hepatic synthesis of bile PC (81). Thus, there is a considerable indirect enterohepatic circulation of choline. Interference with this recirculation may be of crucial importance, e.g., in cystic fibrosis (125) and short bowel syndrome [for ref see Nilsson and Duan (6)]. Table 2 summarizes the pathways for the utilization of the choline part of milk-PC.

\section{The Utilization of Lysophosphatidylethanolamine and Ethanolamine}

Table 2 also summarizes the utilization of the ethanolamine. After the extensive degradation of PE in the proximal jejunum (43), rather small proportions of lyso-PE and plasmalogenic lyso-PE are reacylated into chylomicron and mucosal PE. Some ethanolamine is used for PE synthesis in the mucosa. After milk fat intake, PE transports significant proportions of the ARA and DHA in chyle (116). Of the ethanolamine that is transported via the portal vein, much is incorporated into hepatic PE (43).

Absorbed sphingosine is converted to sphingosine-1phosphate (S1P) by sphingosine kinase. Most of the S1P is converted to palmitaldehyde by S1P-lyase and ethanolaminephosphate (80). Each SM molecule thus generates one choline and one ethanolamine molecule. Since the course of digestion of SM in the gut is more extended than the absorption of PE, milk SM and PE may together supply ethanolamine to the mucosa in the whole small intestine. Ethanolamine has trophic and antioxidative effects on the mucosa (130). S1P is also an important signal substance that may be fundamental to paracrine antiapoptotic signaling and immunoregulation in the mucosa. The partitioning of S1P generated from ingested SM between irreversible degradation by S1P-lyase and paracrine secretion and action on epithelial and immunocyte S1P receptors are of great interest [for ref see (5)]. S1P is found in chyle, but the concentration is lower than in blood. Information on whether concentration in chyle increases after SM feeding is lacking (131). The small intestine expresses the enzymes necessary for synthesis of sphingosine, ceramide, SM, glucosylceramide, and more complex glycosphingolipids [for see Duan and Nilsson (132)]. Although the sphingolipid synthesis is active during the formation of differentiated villi, the incorporation of absorbed sphingoid bases into complex sphingolipids is small. Furthermore, although sphingosine and sphinganine are metabolized similarly, dienoic and hydroxylated sphingoid bases in plant sphingolipids may be less effectively metabolized, some being expelled by the ABCB1 transporter and some transferred to blood as ceramide $(133,134)$.

Ethanolamine is used by many gut bacteria both for oxidation and for synthesis of PE, which is a major PL in gut bacteria (135). Certain intestinal bacteria, including some pathogenic species, use ethanolamine as a carbon and/or $\mathrm{N}$ source with the aid of ethanolamine utilization proteins (EutR). Changes in ethanolamine availability may alter both the colonization of ethanolamine-using bacteria and the virulence of pathogenic bacteria. The Paneth cell phospholipase A2 IIA has high activity against $\mathrm{PE}$ and is bactericidal [for ref see (6)]. The rapid digestion of $\mathrm{PE}$ in the proximal gut combined with the intracellular ethanolamine generation from sphingosine seems well-suited to optimize the ethanolamine assimilation by the host with minimal bacterial interference.

\section{The Targeting of PUFAs to Phospholipids}

The milk fat globule is an energy dense product that which fuels fatty acid oxidation. Medium- and short-chain fatty acids are 
TABLE 2 | Milk phosphatidylcholine (PC) and sphingomyelin (SM) are sources of choline that are used for mucosal PC synthesis or recycled via the portal vein and as chylomicron PC.

\section{Milk polar lipid and post-prandial choline and ethanolamine metabolism}

\section{Event}

Milk SM and PC contribute but are not major sources of choline in the neonate

Reacylation of absorbed lyso-PC, mainly from bile PC, is a major source of chylomicron PC

Use of absorbed choline for mucosal PC synthesis

A major part of the choline from PC and SM is transported as free choline by the portal blood

Limited reacylation of absorbed lyso-PE and plasmalogenic lyso-PE into mucosal and chylomicron PE but active mucosal PE synthesis (43)

Transport of ethanolamine by the portal blood (43)

Mucosal metabolism of absorbed sphingosine from milk SM generates ethanolamine

Course of PE and SM digestion minimize bacterial utilization of ethanolamine (129)

\begin{abstract}
Importance
Milk PC and SM account for 20\%, and cholinephosphate, glycerophophocholine and choline for $80 \%$ in human milk (19) Access of lyso-PC for reacylation determines maximal rate of production and PL/TAG ratio of chylomicrons $(126,127)$

Mucosal PC synthesis is necessary for normal mucosal function and lipid absorption (121)

Effective uptake of choline by the liver and extensive use for PC synthesis. Newly synthesized PC is preferentially secreted as bile PC [for ref see Nilsson and Duan (6)]

Reacylation not necessary for chylomicron production. Yet, nascent chylomicron PLs contain 8-12\% PE (116)

Effective uptake by the liver and extensive use for hepatic PE synthesis (128)

Supplies ethanolamine to the mucosa over a more extended part of the small intestine (81)

PE digestion and absorption is rapid in upper small intestine (43) and sphingosine generatesethanolamineintracellularly
\end{abstract}

Supply of ethanolamine via phosphatidylethanolamine (PE) and via metabolism of the sphingoid bases of SM contribute to mucosal PE formation and the secretion of chylomicron PE, and to hepatic PE synthesis.

preferentially oxidized or converted into ketone bodies in the liver. The fact that suckling babies have a mild ketosis all the time reflects that milk fat metabolism is optimized for glucose sparing even when energy intake is sufficient. In this context, the fatty acids that are needed for the anabolic expansion of tissue PL pools should not be oxidized but selectively targeted to tissue PLs. Table 3 summarizes the pathways by which this occurs.

The preferential partitioning of ARA and other PUFAs to mucosal PC via LPCAT 3 has already been mentioned. The CDPethanolamine pathway prefers molecular species containing DHA or AA in the case of PE formation (128). Selective fatty acid acylation of PUFAs into distinct PLs is a saturable process. With higher concentrations of PUFA-acyl-CoAs available, an increased proportion is incorporated into TAG, e.g., with high LA access, LA-CoA competes with the AA- and DHA-CoA for incorporation into chyle $\mathrm{PC}$ and $\mathrm{PE}$. A larger proportion of all three fatty acids is then partitioned to TAGs, although the preferential incorporation of ARA into PE and PI was rather unaffected (116). Thus, feeding LA- or DHA-rich formulations to neonates may decrease the partitioning of ARA to PLs.

\section{Metabolism of Chylomicron Phospholipids}

The partitioning of PUFAs to chylomicron PLs influences their further metabolism. During the metabolism of chylomicrons, most of the PC, PE, PI, and SM are transferred to HDL via phospholipid transfer protein $(137,143)$. HDL-PC is metabolized mainly by LCAT, hepatic lipase, and uptake to the liver as intact PC via the SRB1 receptor and unknown mechanisms (138). The SR-B1 receptor in the liver also mediates uptake of SM into the hepatocytes. In humans, chylomicron PC, after its transfer to $\mathrm{HDL}$, is metabolized without rapid equilibration with LDL,VLDL, and erythrocyte membrane PC (144). Any
PC-PUFA that is used by LCAT to produce cholesteryl ester is also transported to the liver via lipoprotein receptors and SRB1 receptor-mediated cholesteryl ester uptake. The fatty acid composition of plasma cholesteryl esters both in humans and rats reflects mainly the action of LCAT.

Interestingly, human LCAT, which normally transfers the 2fatty acid in PC, may use fatty acids derived from the sn-1position of 2-ARA-PC or 2-DHA-PC (145). If so, the action of LCAT on HDL-PC, originating from chylomicrons, may generate both saturated 1-lyso-PC and 2-AA and 2-DHA-lysoPC. However, Lyso-PC is also secreted from the liver by the hydrolysis of hepatic PC (139). The major portion of fatty acids in this lyso-PC is also polyunsaturated. The most prevalent PUFA is ARA, followed by LA (139). How this release of lyso-PC from the liver is regulated is poorly known.

The conclusion is that both LCAT action on chylomicronderived PC and hepatic secretion must be quantitatively important sources of lyso-PC. They are also determinants of the fatty acid composition of lyso-PC.

\section{The Quantitative Role of lyso-PC in Choline and Fatty Acid Transport}

Few studies have considered the quantitative aspect of the role of lyso-PC in choline and fatty acid and phospholipid transport. In rats, 1-palmitoyl-lyso-PC (146) and 2-ARA-lysoPCA (147) are eliminated much faster than lipoprotein-PC after iv injection. Combining data from different studies, one finds that lyso-PC concentration in blood is 13-32-fold higher than the concentration of free choline in humans and approximately 50 -fold higher in rats. In rats, the half-life for the initial slope of lyso-PC elimination was 6-11 min (146), which corresponds to a clearance of the order $3-5.6 \mu \mathrm{mol} / \mathrm{kg} / \mathrm{min}$. From data on 
TABLE 3 | Selective targeting of milk polyunsaturated fatty acids (PUFAs) to mucosal and chyle phospholipids (PLS), the metabolism of chyle PLs by LCAT, hepatic lipase and hepatic uptake, and the utilization of PUFAs for the dynamic hepatic PL metabolism are important features.

\section{The selective targeting of milk PUFAs to tissue PLs}

1. Milk LA, ARA and DHA supplied in TAG, PC, PE and plasmalogenic PE are selectively partitioned to mucosal (117)and chylomicron PLs (116) by selective reacylation of lyso-PC, by preferential use of unsaturated diacylglycerol species in the de novo synthesis of PE, and by deacylation reacylation cycles (136)

2. Selective acylation of Iyso-PC with PUFAs via LPCAT3 (110)is essential for chylomicron secretion and normal fat absorption, and a major source of chyle PC. Mucosal de novo synthesis of PC is not selective for PUFAs but essential for normal lipid absorption (121)

3. Little absorbed lyso-PE is recylated into chylomicron PE. Yet chyle lipoprotein PLs contain a significant proportion of PE that is rich in ARA and DHA (116)

4. Chylomicron PC, PE, PI and SM are transferred to HDL by phospholipid transfer protein during the metabolism of the chylomicronTAG by lipoprotein lipase (137)

5. $P C$ in HDL is metabolized by LCAT, hepatic lipase and hepatic uptake of intact PC (138). LCAT may generate both saturated and polyunsaturated lyso-PC species (138)

6. Secretion of polyunsaturated lyso-PC from liver (139) and lyso-PC generated by LCAT is an important transport vehicle for choline and fatty acid to tissues, including Msfa-2 mediated transport of choline and PUFAS into brain (140) and placenta (141)

7. $\mathrm{PE}$ in $\mathrm{HDL}$ is metabolized by hepatic lipase which generates 2-acyl-lyso-PE, and by hepatic uptake of intact PE (142)

8. ARA and DHA esters in chylomicron-TAG partially resistant to lipoprotein lipase and enriched in chylomicron remnants and partitioned to the liver. Some ARA is resecreted in bile PC and is used for mucosal PL formation (118)

Arachidonic acid (ARA) exhibits the highest degree of selective partitioning to these pathways.

the elimination of IV-injected 3H-choline (148) and on the plasma concentration of free choline obtained by others, one may calculate that the turnover of plasma-free choline in rats is of the order $0.7 \mu \mathrm{mol} / \mathrm{kg} / \mathrm{min}$. After injection of 2-ARA-lyso-PC, the liver also exhibited the highest uptake per organ weight. The uptake by the small intestine per $g$ was about half and the uptake per $g$ by the brain was about one-tenth of that in the liver (147). Thus, lyso-PC is an important carrier of both saturated fatty acids, PUFAs including ARA and DHA, and choline to tissues. In parallel, there is a transporter-mediated uptake of free choline, including high-affinity transporter, for acetylcholine formation in neurons (149-151).

A role of lyso-PC in the transfer of PUFAs as AA, DHA, and choline over the blood brain barrier has long been advocated $(139,147,152-154)$. Recently, a role of the transporter mfsd 2a (from the major facilitator superfamily 2a, a previously orphan transporter) in the uptake of DHA-lyso-PC (140) has been established. This transporter is expressed in the endothelium of the blood-brain barrier of microvessels (140). Any dietary influence on the formation of different molecular lyso-PC species may hereby be linked to an influence on the brain supply of choline and PUFAs. Defect mfsd 2a has been linked to developmental defects of the brain (155).

\section{Lyso-PC Traffic Early in Life}

In premature babies, PC levels increase via the formation of PC via the CDP-choline pathway weeks after birth (156). Since the PEMT is poorly expressed, the rate of formation of AA and DHA molecular species may be restricted, whereas, in utero, both choline and PUFAs are supplied indirectly via the PEMT pathway of the mother. The supply of both choline and the long-chain PUFAs AA and DHA has, therefore, been advocated (157).

After birth, the plasma level of PC increases during the first 4 months of life (158). At the same time, the proportion of AA in both PC and LPC decreases and linoleate increases (158). Thus, during the intrauterine life during which fatty acids are not used much for energy production, the fatty acid composition of plasma PC is rather similar to that of liver tissue. During suckling, when LA and oleic acid are supplied, elongation-desaturation of LA becomes the major source of tissue ARA and lipoproteins transport more fatty acids for oxidation and energy storage. This is also reflected in the fatty acid composition of PC.

Lyso-PC may also be an important transporter for the supply of choline and PUFAs to the fetus in utero. The expression of the Mfsd transporter in the placenta may be of key importance (141). An early study (159) found a remarkably high uptake into the placenta after IV injection of $3 \mathrm{H}$-labeled lyso-PC in pregnant rats.

\section{Postprandial Metabolism of Ethanolamine}

Chyle chylomicrons and nascent VLDL contain a larger proportion of PE than blood lipoproteins (116). After the transfer of PE to HDL, it is rapidly cleared by the action of hepatic lipase (142), which generates highly unsaturated 2-acyl-lyso-PE. The uptake by the liver is high, but lyso-PE also delivers PUFAs and ethanolamine to other tissues $(142,146)$. However, quantitative studies of the uptake of lyso-PE into the brain and of the role of the $\mathrm{mfsd} 2 \mathrm{a}$ transporter in the uptake of lyso-PE into the brain are lacking.

Free ethanolamine in the portal vein is extensively used for hepatic PE synthesis (128). Furthermore, PE synthesis in hepatocytes increases with access to ethanolamine up to a saturation level when ethanolamine-phosphate accumulates (160). In mammalian cells, PE is synthesized by the CDPethanolamine pathway and the PS decarboxylation pathway, which operate in the endoplasmic reticulum and mitochondria, respectively (136).

The conclusion is that ethanolamine and PE in milk contribute both to the transport of PUFA and ethanolamine to tissues and to a highly active hepatic PE synthesis, which, in turn, may favor the formation of highly unsaturated PC species via PEMT.

\section{Metabolism of Arachidonic Acid and Long-Chain n-3 Fatty Acid Esters in Chylomicrons}

Some AA and DHA are incorporated into the chyle TAGs. The AA and DHA esters of chylomicron TAGs are, in part, resistant to lipoprotein lipase, and are, therefore, transported to the liver with 
the chylomicron remnants $(161,162)$. In rats, chylomicron AA contributes significantly to bile PC-AA and mucosal AA pools via bile secretion (118).

\section{POST-PRANDIAL EFFECTS OF MILK POLAR LIPIDS}

The potential health effects of milk polar lipids have recently been reviewed $(4,163)$. Here, we commented on the post-prandial effects that milk polar lipids may have on post-prandial PL and TAG metabolism. Animal studies have shown that feeding PC decreases the size of chylomicrons and increases the PC/TAG ratio of the post-prandial lipoproteins [for ref see Nilsson and Duan (6)]. This, in turn, may be linked to a raise in HDL-PC and the size of HDL particles [for see Anto and Warykas (4)].

The numerous factors that influence the post-prandial response to lipids in a meal have been summarized (164). With a Western diet rich in butter fat, the post-prandial TAG-rich lipoprotein particles were more plentiful and smaller than with a Mediterranean-type diet (165). Ingestion of 42-50-g butter resulted in lower post-prandial TAG than the equivalent amount of olive oil in men (166). The lower increase in plasma TAG after intake of butter can be related to the course of digestion and the fatty acid composition with high-content saturated and medium- and short-chain fatty acids (166). Studies of different dairy products have shown that cream cheese induced a larger increase in post-prandial TAG than butter and cheddar cheese, which was suggested to be linked to the disintegration rate of the product in the gut (167).

When comparing the post-prandial effects of soy and milk PL on lipid metabolism in mice, emulsification with PL resulted in a faster increase in plasma TAG but also in a faster plasma clearance and lower TAG levels after $4 \mathrm{~h}$. The findings were correlated with a faster duodenal lipolysis of the milk PLemulsified lipids (168). Interestingly in an 8-week study on obese patients who included either 40-g milk fat as butter oil or whip cream in their diets, the whip cream group did not exhibit the negative effects on lipid parameters as much as the butter oil group (169). Thus, the question of whether a faster course of absorption favors the partitioning of fatty acids to hepatic oxidation is of great interest.

A lipidomic study analyzed post-prandial plasma lipids after intake of a dairy meal (cheddar cheese, butter, and creamy whole milk) compared to a soy meal with vegetable oil. Both meals contained 54-g fat (170). No difference was seen in postprandial TAG or cholesterol levels. Although one would expect an increased production of chylomicron PC post-prandially, PC levels were only modestly increased after the dairy meal and unchanged after the soy meal. Changes in distinct molecular species reflected the presence of odd-chain fatty acids in milk and the increased level of LA in the soy lipids. Lyso-PC levels were unchanged after the dairy meal and decreased after the soy meal. Earlier studies showed that, when a mixed meal with 0-50-g fat was given, post-prandial total PL levels decreased significantly after a fat-free meal and increased slightly only with the higher fat doses (171). An increased production of chylomicron and VLDL PC after a meal may thus be balanced by increased post-prandial elimination of PLs. Furthermore, PE and lyso-PE increased similarly after both meals, reflecting the secretion of PE in nascent chylomicrons and VLDL (170). Several SM species increased after the dairy meal and decreased after the soy meal. Although this might reflect a transfer of intact milk SM into blood, it may also result from the high content of palmitic acid in the milk fat and the effects of saturated fatty acids on lipoprotein formation.

Differences in minor PL fractions were observed, which may be potentially relevant, e.g., there was a $34 \%$ increase of lysoPI after the dairy meal but only a $10 \%$ increase after the soy meal, which may have implications for fat deposition (172). Chylomicron-PI is a small fraction in chyle but is rich in ARA and is metabolized slower than PE, mainly by hepatic uptake and possibly hepatic lipase (173). Furthermore, alkyl-PC, alkenyl-PC, and alkyl-PE were increased after the dairy meal but decreased after the soy meal, which may be of importance since ether lipids and plasmalogens are negatively associated with metabolic disease (174).

In conclusion, polar milk lipids may be linked both to the course of digestion of other milk lipids and to dose-dependent complex changes in the post-prandial PL pattern. Postprandial metabolomics studies with an increasing dose of MFGM polar lipids are so far lacking. Whether milk polar lipids may be linked to other interesting effects of dairy products, such as effects on release of satiety hormones (175) and anti-inflammatory effects $(176,177)$, is unknown.

\section{CONCLUSIONS AND PERSPECTIVES}

Milk PC and PE are both hydrolyzed by sPLA2 IB in the upper small intestine, but the PC hydrolysis is more extended and PLB is likely to be involved to a larger degree. Both the selective reacylation of lyso-PC and the use of choline and ethanolamine for the production of mucosal and chylomicron PLs are essential for normal lipid absorption and chylomicron production. The later phase of the PC hydrolysis coincides with SM hydrolysis by alk-SMase and N-CDase. The hydrolysis of PC and SM in mixed bile salt/PL/cholesterol micelles favors cholesterol absorption, which is specifically inhibited by the presence of SM. The dose of MFGM polar lipids required to demonstrate a significant effect in humans is relatively large.

In neonates, the MFGM provides physical properties to the milk fat globule that enhances TAG digestion. The proportion of polar lipids in milk fat globules is much lower than in the chyle lipoproteins. Reacylation of lyso-PC from milk PC is also a contributing but not a major source of PC for chylomicron secretion; mucosal PL synthesis and reacylation of lyso-PC from bile PC must also contribute. Although PLRP2, alk-SMase, and $\mathrm{N}$-CDase are expressed at birth, the course of polar milk lipid digestion in neonates is poorly characterized.

The access of the gut to milk polar lipids and water-soluble choline and ethanolamine favors mucosal and hepatic PC and $\mathrm{PE}$ generation. The ARA from milk PE and TAG is selectively retained in mucosal PC, PE, and PI, and is selectively transported 
with chylomicron PC, PE, and chylomicron remnants. This favors the uptake of ARA by the liver. Furthermore, LCAT probably generates both saturated and unsaturated lyso-PC species. The metabolism of chylomicron PLs and TAGs after feeding milk fat thus contributes nitrogen bases and PUFAs to both the high PL turnover in the liver and to the lyso-PC formation that transports both fatty acids and nitrogen bases to extrahepatic tissues, including the brain. Recent studies have exemplified that analysis of time courses using stable isotopes $(156,178)$ will clarify the nutritional, diurnal, and developmental regulations of these pathways in the near future.

Other important areas for future studies are the possible links between SM supply and digestion and SIP paracrine signaling between the supply of choline PLs and epithelial acetyl-choline formation. The links between the supply of PE and SM and the trophic and antioxidative effects of ethanolamine are also of interest.

\section{REFERENCES}

1. Heid HW, Keenan TW. Intracellular origin and secretion of milk fat globules. Eur J Cell Biol. (2005) 84:245-58. doi: 10.1016/j.ejcb.2004.12.002

2. Norris GH, Milard M, Michalski MC, Blesso CN. Protective properties of milk sphingomyelin against dysfunctional lipid metabolism, gut dysbiosis, and inflammation. J Nutr Biochem. (2019) 73:108224. doi: 10.1016/j.jnutbio.2019.108224

3. Rohrhofer J, Zwirzitz B, Selberherr E, Untersmayr E. The impact of dietary sphingolipids on intestinal microbiota and gastrointestinal immune homeostasis. Front Immunol. (2021) 12:635704. doi: 10.3389/fimmu.2021.635704

4. Anto L, Warykas SW, Torres-Gonzalez M, Blesso CN. Milk polar lipids: underappreciated lipids with emerging health benefits. Nutrients. (2020) 12:1001. doi: 10.3390/nu12041001

5. Nilsson A. Role of sphingolipids in infant gut health and immunity. J Pediatr. (2016) 173 (Suppl):S53-9. doi: 10.1016/j.jpeds.2016.02.076

6. Nilsson A, Duan RD. Pancreatic and mucosal enzymes in choline phospholipid digestion. Am J Physiol Gastrointest Liver Physiol. (2019) 316:G425-45. doi: 10.1152/ajpgi.00320.2018

7. Lopez C. Milk fat globules enveloped by their biological membrane: unique colloidalassemblies with a specific composition and structure. Curr Opin Colloid Interface Sci. (2011) 16:391-404. doi: 10.1016/j.cocis.2011.05.007

8. Delplanque B, Gibson R, Koletzko B, Lapillonne A, Strandvik B. Lipid quality in infant nutrition: current knowledge and future opportunities. J Pediatr Gastroenterol Nutr. (2015) 61:8-17. doi: 10.1097/MPG.0000000000000818

9. Contarini G, Povolo M. Phospholipids in milk fat: composition, biological and technological significance, and analytical strategies. Int J Mol Sci. (2013) 14:2808-31. doi: 10.3390/ijms14022808

10. Duan B, Hong ES, Shin JA, Qin Y, Lee JH, Lee CW, et al. Correlations of fat content in human milk with fat droplet size and phospholipid species. Molecules. (2021) 26:1596. doi: 10.3390/molecules26061596

11. Giuffrida F, Cruz-Hernandez C, Fluck B, Tavazzi I, Thakkar SK, Destaillats F, et al. Quantification of phospholipids classes in human milk. Lipids. (2013) 48:1051-8. doi: 10.1007/s11745-013-3825-z

12. Thakkar SK, Giuffrida F, Cristina CH, De Castro CA, Mukherjee R, Tran LA, et al. Dynamics of human milk nutrient composition of women from Singapore with a special focus on lipids. Am J Hum Biol. (2013) 25:7709. doi: 10.1002/ajhb.22446

13. Wei W, Yang J, Yang D, Wang X, Yang Z, Jin Q, et al. Phospholipid composition and fat globule structure i: comparison of human milk fat from different gestational ages, lactation stages, and infant formulas. J Agric Food Chem. (2019) 67:13922-8. doi: 10.1021/acs.jafc. $9 \mathrm{~b} 04247$
Although interactions with the gut microbiome are important, it is also worth emphasizing that the pancreatic and mucosal enzymes together optimize the digestion of MFGM PLs in a way that normally restricts bacterial access to the ethanolamine and choline parts.

\section{AUTHOR CONTRIBUTIONS}

All authors listed have made a substantial, direct and intellectual contribution to the work, and approved it for publication.

\section{FUNDING}

The previous work by the authors that was cited in this study was, at the time, supported by grants from the Swedish Research Council, the Swedish Cancer Society, the Albert Påhlsson Foundation, and by ALF-grants (grants for clinical science).

14. Ma L, MacGibbon AK, Mohamed HJBJ, Loy S, Rowan A, McJarrow $\mathrm{P}$, et al. Determination of phospholipid concentrations in breast milk and serum using a high performance liquid chromatography-mass spectrometry-multiple reaction monitoring method. Int Dairy J. (2017) 71:50-9. doi: 10.1016/j.idairyj.2017.03.005

15. Claumarchirant L, Cilla A, Matencio E, Sanchez-Siles LM, CastroGomez P, Fontecha J, et al. Addition of milk fat globule membrane as an ingredient of infant formulas for resembling the polar lipids of human milk. Int Dairy J. (2016) 61:228-38. doi: 10.1016/j.idairyj.2016. 06.005

16. Pimentel L, Gomes A, Pintado M, Rodriguez-Alcala LM. Isolation and analysis of phospholipids in dairy foods. J Anal Methods Chem. (2016) 2016:9827369. doi: 10.1155/2016/9827369

17. Graves EL, Beaulieu AD, Drackley JK. Factors affecting the concentration of sphingomyelin in bovine milk. J Dairy Sci. (2007) 90:706-15. doi: 10.3168/jds.S0022-0302(07)71554-0

18. Lopez C, Briard-Bion V, Menard O, Rousseau F, Pradel P, Besle JM. Phospholipid, sphingolipid, and fatty acid compositions of the milk fat globule membrane are modified by diet. J Agric Food Chem. (2008) 56:522636. doi: 10.1021/jf7036104

19. Holmes-McNary MQ, Cheng WL, Mar MH, Fussell S, Zeisel SH. Choline and choline esters in human and rat milk and in infant formulas. Am J Clin Nutr. (1996) 64:572-6. doi: 10.1093/ajcn/64.4.572

20. Patel D, Witt SN. Ethanolamine and phosphatidylethanolamine: partners in health and disease. Oxid Med Cell Longev. (2017) 2017:4829180. doi: 10.1155/2017/4829180

21. Moukarzel S, Dyer RA, Keller BO, Elango R, Innis SM. Human milk plasmalogens are highly enriched in long-chain PUFAs. J Nutr. (2016) 146:2412-7. doi: 10.3945/jn.116.236802

22. Burling HGG. Milk - a new source for bioactive phospholipids for use in food formulations. Lipid Technol. (2008) 20:229-31. doi: 10.1002/lite.200800058

23. Konrad G, Kleinschmidt T, Lorenz, C. Ultrafiltration of whey buttermilk to obtain a phospholipid concentrate. Int Dairy J. (2013) 30:3944. doi: 10.1016/j.idairyj.2012.11.007

24. He X, McClorry S, Hernell O, Lonnerdal B, Slupsky CM. Digestion of human milk fat in healthy infants. Nutr Res. (2020) 83:15-29. doi: 10.1016/j.nutres.2020.08.002

25. Koletzko B, Rodriguez-Palmero M, Demmelmair H, Fidler N, Jensen R, Sauerwald T. Physiological aspects of human milk lipids. Early Hum Dev. (2001) 65 (Suppl):S3-18. doi: 10.1016/S0378-3782(01)00204-3

26. Mathiassen JH, Nejrup RG, Frokiaer H, Nilsson, A., Ohlsson L, Hellgren LI. Emulsifying triglycerides with dairy phospholipids instead of soy lecithin modulates gut lipase activity. Eur J Lipid Sci Tech. (2015) 117:152239. doi: 10.1002/ejlt.201400505 
27. Bach Korsholm Knudsen K, Heerup C, Rongaard Stange Jensen T, Geng X, Drachmann N, Nordby P, et al. Bovine milk-derived emulsifiers increase triglyceride absorption in newborn formula-fed pigs. Nutrients. (2021) 13:410. doi: 10.3390/nu13020410

28. Abrahamse E, Minekus M, van Aken GA, van de Heijning B, Knol J, Bartke N, et al. Development of the digestive system-experimental challenges and approaches of infant lipid digestion. Food Dig. (2012) 3:6377. doi: 10.1007/s13228-012-0025-x

29. Rings EH, Minich DM, Vonk RJ, Stellaard F, Fetter WP, Verkade HJ. Functional development of fat absorption in term and preterm neonates strongly correlates with ability to absorb longchain Fatty acids from intestinal lumen. Pediatr Res. (2002) 51:57-63. doi: 10.1203/00006450-200201000-00011

30. Weaver LT, Austin S, Cole TJ. Small intestinal length: a factor essential for gut adaptation. Gut. (1991) 32:1321-3. doi: 10.1136/gut.32.11.1321

31. Koletzko B, Lien E, Agostoni C, Bohles H, Campoy C, Cetin I, et al. The roles of long-chain polyunsaturated fatty acids in pregnancy, lactation and infancy: review of current knowledge and consensus recommendations. $J$ Perinat Med. (2008) 36:5-14. doi: 10.1515/JPM.2008.001

32. Bernhard W, Full A, Arand J, Maas C, Poets CF, Franz AR. Choline supply of preterm infants: assessment of dietary intake and pathophysiological considerations. Eur J Nutr. (2013) 52:1269-78. doi: 10.1007/s00394-012-0438-x

33. Innis SM, Adamkin DH, Hall RT, Kalhan SC, Lair C, Lim M, et al. Docosahexaenoic acid and arachidonic acid enhance growth with no adverse effects in preterm infants fed formula. J Pediatr. (2002) 140:54754. doi: $10.1067 / \mathrm{mpd} .2002 .123282$

34. Vors C, Pineau G, Gabert L, Drai J, Louche-Pelissier C, Defoort C, et al. Modulating absorption and postprandial handling of dietary fatty acids by structuring fat in the meal: a randomized crossover clinical trial. Am J Clin Nutr. (2013) 97:23-36. doi: 10.3945/ajcn.112.043976

35. Carey MC, Small DM, Bliss CM. Lipid digestion and absorption. Annu Rev Physiol. (1983) 45:651-77. doi: 10.1146/annurev.ph.45.030183.003251

36. Borgstrom B. Importance of phospholipids, pancreatic phospholipase A2, and fatty acid for the digestion of dietary fat: in vitro experiments with the porcine enzymes. Gastroenterology. (1980) 78(5 Pt. 1):95462. doi: 10.1016/0016-5085(80)90777-5

37. Borgstrom B, Erlanson-Albertsson C. Hydrolysis of milk fat globules by pancreatic lipase. Role of colipase, phospholipase A2, and bile salts. J Clin Invest. (1982) 70:30-2. doi: 10.1172/JCI110599

38. Tojo H, Ichida T, Okamoto M. Purification and characterization of a catalytic domain of rat intestinal phospholipase B/lipase associated with brush border membranes. J Biol Chem. (1998) 273:2214-21. doi: 10.1074/jbc.273.4.2214

39. Sato H, Isogai Y, Masuda S, Taketomi Y, Miki Y, Kamei D, et al. Physiological roles of group $\mathrm{X}$-secreted phospholipase A2 in reproduction, gastrointestinal phospholipid digestion, and neuronal function. J Biol Chem. (2011) 286:11632-48. doi: 10.1074/jbc.M110.206755

40. Tchoua U, Ito M, Okamoto M, Tojo H. Increased intestinal phospholipase $\mathrm{A}(2)$ activity catalyzed by phospholipase B/lipase in WBN/Kob rats with pancreatic insufficiency. Biochim Biophys Acta. (2000) 1487:25567. doi: 10.1016/S1388-1981(00)00101-3

41. Andersson L, Sternby B, Nilsson A. Hydrolysis of phosphatidylethanolamine by human pancreatic phospholipase A2. Effect of bile salts. Scand J Gastroenterol. (1994) 29:182-7. doi: 10.3109/00365529409090460

42. Lowe ME. The triglyceride lipases of the pancreas. J Lipid Res. (2002) 43:2007-16. doi: 10.1194/jlr.R200012-JLR200

43. Ikeda I, Imaizumi K, Sugano M. Absorption and transport of base moieties of phosphatidylcholine and phosphatidylethanolamine in rats. Biochim Biophys Acta. (1987) 921:245-53. doi: 10.1016/0005-2760(87)90024-5

44. Barros H, Sternby B, Nilsson A. Hydrolysis of phosphatidylinositol by human pancreatic phospholipase A2. Scand J Gastroenterol. (1990) 25:13440. doi: 10.3109/00365529009107934

45. Verger R, Ferrato F, Mansbach CM, Pieroni G. Novel intestinal phospholipase A2: purification and some molecular characteristics. Biochemistry. (1982) 21:6883-9. doi: 10.1021/bi00269a040

46. Harwig SS, Tan L, Qu XD, Cho Y, Eisenhauer PB, Lehrer RI. Bactericidal properties of murine intestinal phospholipase A2. J Clin Invest. (1995) 95:603-10. doi: 10.1172/JCI117704
47. Wu LC, Pfeiffer DR, Calhoon EA, Madiai F, Marcucci G, Liu S, et al. Purification, identification, and cloning of lysoplasmalogenase, the enzyme that catalyzes hydrolysis of the vinyl ether bond of lysoplasmalogen. J Biol Chem. (2011) 286:24916-30. doi: 10.1074/jbc.M111.247163

48. Li X, Lindquist S, Lowe M, Noppa L, Hernell O. Bile salt-stimulated lipase and pancreatic lipase-related protein 2 are the dominating lipases in neonatal fat digestion in mice and rats. Pediatr Res. (2007) 62:53741. doi: 10.1203/PDR.0b013e3181559e75

49. Wacker H, Keller P, von Balthazar AK, Semenza G. "Adult only" esterase/phospholipase A of the small-intestine brush border membrane: isolation, identification of the catalytic site, and biosynthesis. Biochemistry. (1997) 36:3336-44. doi: 10.1021/bi962398a

50. Boll W, Schmid-Chanda T, Semenza G, Mantei N. Messenger RNAs expressed in intestine of adult but not baby rabbits. Isolation of cognate cDNAs and characterization of a novel brush border protein with esterase and phospholipase activity. J Biol Chem. (1993) 268:1290111. doi: 10.1016/S0021-9258(18)31471-6

51. Taylor JK, Boll W, Levy T, Suh E, Siang S, Mantei N, et al. Comparison of intestinal phospholipase A/lysophospholipase and sucrase-isomaltase genes suggest a common structure for enterocyte-specific promoters. DNA Cell Biol. (1997) 16:1419-28. doi: 10.1089/dna.1997.16.1419

52. Holopainen R, Aho H, Laine J, Peuravuori H, Soukka H, Kaapa P. Human meconium has high phospholipase A2 activity and induces cellular injury and apoptosis in piglet lungs. Pediatr Res. (1999) 46:626-32. doi: 10.1203/00006450-19991100000022

53. Schrama AJ, de Beaufort AJ, Sukul YR, Jansen SM, Poorthuis BJ, Berger HM. Phospholipase A2 is present in meconium and inhibits the activity of pulmonary surfactant: an in vitro study. Acta Paediatr. (2001) 90:4126. doi: 10.1080/08035250119062

54. Venuti E, Shishmarev D, Kuchel PW, Dutt S, Blumenthal CS, Gaskin KJ. Bile salt stimulated lipase: Inhibition by phospholipids and relief by phospholipase A2. J Cyst Fibros. (2017) 16:76370. doi: 10.1016/j.jcf.2017.07.005

55. Nyberg L. Digestion and Absorption of Sphingomyelin From Milk. (Ph.D., Thesis), Department of Internal Medicine, Medical Faculty, Lund University (Lund: Sweden) (1998).

56. Nilsson A. The presence of spingomyelin- and ceramide-cleaving enzymes in the small intestinal tract. Biochim Biophys Acta. (1969) 176:33947. doi: 10.1016/0005-2760(69)90192-1

57. Cheng Y, Nilsson A, Tomquist E, Duan RD. Purification, characterization, and expression of rat intestinal alkaline sphingomyelinase. J Lipid Res. (2002) 43:316-24. doi: 10.1016/S0022-2275(20)30174-7

58. Duan RD, Bergman T, Xu N, Wu J, Cheng Y, Duan J, et al. Identification of human intestinal alkaline sphingomyelinase as a novel ecto-enzyme related to the nucleotide phosphodiesterase family. J Biol Chem. (2003) 278:3852836. doi: 10.1074/jbc.M305437200

59. van Meeteren LA, Moolenaar WH. Regulation and biological activities of the autotaxin-LPA axis. Prog Lipid Res. (2007) 46:145-60. doi: 10.1016/j.plipres.2007.02.001

60. Zimmermann $H$, Zebisch $M$, Strater N. Cellular function and molecular structure of ecto-nucleotidases. Purinergic Signal. (2012) 8:437-502. doi: 10.1007/s11302-012-9309-4

61. Wu J, Liu F, Nilsson A, Duan RD. Pancreatic trypsin cleaves intestinal alkaline sphingomyelinase from mucosa and enhances the sphingomyelinase activity. Am J Physiol Gastrointest Liver Physiol. (2004) 287:G96773. doi: 10.1152/ajpgi.00190.2004

62. Duan RD, Hertervig E, Nyberg L, Hauge T, Sternby B, Lillienau J, et al. Distribution of alkaline sphingomyelinase activity in human beings and animals. Tissue and species differences. Dig Dis Sci. (1996) 41:18016. doi: 10.1007/BF02088748

63. Zhang Y, Cheng Y, Hansen GH, Niels-Christiansen LL, Koentgen F, Ohlsson $\mathrm{L}$, et al. Crucial role of alkaline sphingomyelinase in sphingomyelin digestion: a study on enzyme knockout mice. J Lipid Res. (2011) 52:77181. doi: 10.1194/jlr.M012880

64. Nyberg L, Duan RD, Axelson J, Nilsson A. Identification of an alkaline sphingomyelinase activity in human bile. Biochim Biophys Acta. (1996) 1300:42-8. doi: 10.1016/0005-2760(95)00245-6 
65. Duan RD, Nilsson A. Purification of a newly identified alkaline sphingomyelinase in human bile and effects of bile salts and phosphatidylcholine on enzyme activity. Hepatology. (1997) 26:823-30. doi: 10.1002/hep.510260403

66. Lillienau J, Cheng Y, Nilsson A, Duan RD. Development of intestinal alkaline sphingomyelinase in rat fetus and newborn rat. Lipids. (2003) 38:545-9. doi: 10.1007/s11745-0031340-1

67. Duan RD, Cheng Y, Jonsson BA, Ohlsson L, Herbst A, HellstromWestas L, et al. Human meconium contains significant amounts of alkaline sphingomyelinase, neutral ceramidase, and sphingolipid metabolites. Pediatr Res. (2007) 61:61-6. doi: 10.1203/01.pdr.0000250534.92 934.c2

68. Irino $\mathrm{T}$, Matsushita $\mathrm{M}$, Sakagishi $\mathrm{Y}, \quad$ Komoda $\mathrm{T}$. Phosphorylcholine as a unique substrate for human intestinal alkaline phosphatase. Int $J$ Biochem. (1994) 2 6:273-7.

69. Duan RD, Nyberg L, Nilsson A. Alkaline sphingomyelinase activity in rat gastrointestinal tract: distribution and characteristics. Biochim Biophys Acta. (1995) 1259:49-55. doi: 10.1016/0005-2760(95)0 0137-2

70. Takahashi I, Takahashi T, Abe T, Watanabe W, Takada G. Distribution of acid sphingomyelinase in human various body fluids. Tohoku J Exp Med. (2000) 192:61-6. doi: 10.1620/tjem.192.61

71. Nyberg L, Farooqi A, Blackberg L, Duan RD, Nilsson A, Hernell O. Digestion of ceramide by human milk bile salt-stimulated lipase. J Pediatr Gastroenterol Nutr. (1998) 27:560-7. doi: 10.1097/00005176-199811000-00013

72. Nilsson A. Metabolism of sphingomyelin in the intestinal tract of the rat. Biochim Biophys Acta. (1968) 164:57584. doi: 10.1016/0005-2760(68)90187-2

73. Olsson M, Duan RD, Ohlsson L, Nilsson A. Rat intestinal ceramidase: purification, properties, and physiological relevance. Am J Physiol Gastrointest Liver Physiol. (2004) 287:G929-37. doi: 10.1152/ajpgi.0015 5.2004

74. Ohlsson L, Palmberg C, Duan RD, Olsson M, Bergman T, Nilsson A. Purification and characterization of human intestinal neutral ceramidase. Biochimie. (2007) 89:950-60. doi: 10.1016/j.biochi.2007. 03.009

75. Tani M, Okino N, Mori K, Tanigawa $\mathrm{T}$, Izu H, Ito M. Molecular cloning of the full-length cDNA encoding mouse neutral ceramidase. A novel but highly conserved gene family of neutral/alkaline ceramidases. J Biol Chem. (2000) 275:11229-34. doi: 10.1074/jbc.275.15. 11229

76. Mitsutake S, Tani M, Okino N, Mori K, Ichinose S, Omori $\mathrm{A}$, et al. Purification, characterization, molecular cloning, and subcellular distribution of neutral ceramidase of rat kidney. J Biol Chem. (2001) 276:26249-59. doi: 10.1074/jbc.M1022 33200

77. Tani M, Ito M, Igarashi $Y$. Ceramide/sphingosine/sphingosine 1phosphate metabolism on the cell surface and in the extracellular space. Cell Signal. (2007) 19:229-37. doi: 10.1016/j.cellsig.2006. 07.001

78. Duan RD, Verkade HJ, Cheng Y, Havinga R, Nilsson A. Effects of bile diversion in rats on intestinal sphingomyelinases and ceramidase. Biochim Biophys Acta. (2007) 1771:196-201. doi: 10.1016/j.bbalip.2006. 12.001

79. Kono M, Dreier JL, Ellis JM, Allende ML, Kalkofen DN, Sanders KM, et al. Neutral ceramidase encoded by the Asah2 gene is essential for the intestinal degradation of sphingolipids. J Biol Chem. (2006) 281:7324-31. doi: 10.1074/jbc.M5083 82200

80. Nilsson A, Duan RD. Absorption and lipoprotein transport of sphingomyelin. J Lipid Res. (2006) 47:154-71. doi: 10.1194/jlr.M500357JLR200

81. Nyberg L. Nilsson A, Lundgren P, Duan RD. Localization and capacity of sphingomyelin digestion in the rat intestinal tract. J Nutr Biochem. (1997) 8:112-8. doi: 10.1016/S0955-2863(97)0 0010-7
82. Ohlsson L, Hertervig E, Jonsson BA, Duan RD, Nyberg L, Svernlov R, et al. Sphingolipids in human ileostomy content after meals containing milk sphingomyelin. Am J Clin Nutr. (2010) 91:672-8. doi: 10.3945/ajcn.2009. 28311

83. Le Barz M, Vors C, Combe E, Joumard-Cubizolles L, Lecomte M, Joffre F, et al. Milk polar lipids favorably alter circulating and intestinal ceramide and sphingomyelin species in postmenopausal women. JCI Insight. (2021) 6:e146161. doi: 10.1172/jci.insight.1 46161

84. Sjoqvist U, Hertervig E, Nilsson A, Duan RD, Ost A, Tribukait $\mathrm{B}$, et al. Chronic colitis is associated with a reduction of mucosal alkaline sphingomyelinase activity. Inflamm Bowel Dis. (2002) 8:25863. doi: 10.1097/00054725-200207000-00004

85. Zhang P, Li B, Gao S, Duan RD. Dietary sphingomyelin inhibits colonic tumorigenesis with an up-regulation of alkaline sphingomyelinase expression in ICR mice. Anticancer Res. (2008) 28:3631-5.

86. Cheng Y, Ohlsson L, Duan RD. Psyllium and fat in diets differentially affect the activities and expressions of colonic sphingomyelinases and caspase in mice. Br J Nutr. (2004) 91:715-23. doi: 10.1079/BJN200 41107

87. Liu JJ, Nilsson A, Duan RD. Effects of phospholipids on sphingomyelin hydrolysis induced by intestinal alkaline sphingomyelinase: an in vitro study. J Nutr Biochem. (2000) 11:192-7. doi: 10.1016/S0955-2863(00)00064-4

88. Liu JJ, Nilsson A, Duan RD. In vitro effects of fat, FA, and cholesterol on sphingomyelin hydrolysis induced by rat intestinal alkaline sphingomyelinase. Lipids. (2002) 37:46974. doi: 10.1007/s11745-002-0919-x

89. Cohn JS, Kamili A, Wat E, Chung RW, Tandy S. Dietary phospholipids and intestinal cholesterol absorption. Nutrients. (2010) 2:116-27. doi: 10.3390/nu2020116

90. Young SC, Hui DY. Pancreatic lipase/colipase-mediated triacylglycerol hydrolysis is required for cholesterol transport from lipid emulsions to intestinal cells. Biochem J. (1999) 339 (Pt. 3):615-20. doi: 10.1042/bj3390615

91. Ohvo-Rekila H, Ramstedt B, Leppimaki P, Slotte JP. Cholesterol interactions with phospholipids in membranes. Prog Lipid Res. (2002) 41:6697. doi: 10.1016/S0163-7827(01)00020-0

92. Slotte JP. Biological functions of sphingomyelins. Prog Lipid Res. (2013) 52:424-37. doi: 10.1016/j.plipres.2013.05.001

93. Tai P, Golding M, Singh H, Waterland M, Everett D. CholesterolPhospholipid interactions resist the detergent effect of bovine bile. Colloids Surf B Biointerfaces. (2021) 205:111842. doi: 10.1016/j.colsurfb.2021.111842

94. Duan RD, Nilsson A. A mutual inhibitory effect on absorption of sphingomyelin and cholesterol. J Nutr Biochem. (2000) 11:244-9. doi: 10.1016/S0955-2863(00)00069-3

95. Ko CW, Qu J, Black DD, Tso P. Regulation of intestinal lipid metabolism: current concepts and relevance to disease. Nat Rev Gastroenterol Hepatol. (2020) 17:169-83. doi: 10.1038/s41575-019-0250-7

96. Noh SK, Koo SI. Egg sphingomyelin lowers the lymphatic absorption of cholesterol and alpha-tocopherol in rats. J Nutr. (2003) 133:35716. doi: 10.1093/jn/133.11.3571

97. Eckhardt ER, Wang DQ, Donovan JM, Carey MC. Dietary sphingomyelin suppresses intestinal cholesterol absorption by decreasing thermodynamic activity of cholesterol monomers. Gastroenterology. (2002) 122:94856. doi: 10.1053/gast.2002.32539

98. Vors C, Joumard-Cubizolles L, Lecomte M, Combe E, Ouchchane L, Drai J, et al. Milk polar lipids reduce lipid cardiovascular risk factors in overweight postmenopausal women: towards a gut sphingomyelin-cholesterol interplay. Gut. (2020) 69:487-501. doi: 10.1136/gutjnl-2018-318155

99. Noh SK, Koo SI. Milk sphingomyelin is more effective than egg sphingomyelin in inhibiting intestinal absorption of cholesterol and fat in rats. J Nutr. (2004) 134:2611-6. doi: 10.1093/jn/134.10.2611

100. Kamili A, Wat E, Chung RW, Tandy S, Weir JM, Meikle PJ, et al. Hepatic accumulation of intestinal cholesterol is decreased and fecal cholesterol excretion is increased in mice fed a high-fat diet supplemented with milk phospholipids. Nutr Metab. (2010) 7:90. doi: 10.1186/1743-7075-7-90

101. Zhang P, Chen Y, Cheng Y, Hertervig E, Ohlsson L, Nilsson A, et al. Alkaline sphingomyelinase (NPP7) promotes cholesterol absorption by affecting sphingomyelin levels in the gut: a study with NPP7 
knockout mice. Am J Physiol Gastrointest Liver Physiol. (2014) 306:G9038. doi: 10.1152/ajpgi.00319.2013

102. Feng D, Ohlsson L, Ling W, Nilsson A, Duan RD. Generating ceramide from sphingomyelin by alkaline sphingomyelinase in the gut enhances sphingomyelin-induced inhibition of cholesterol uptake in Caco-2 cells. Dig Dis Sci. (2010) 55:3377-83. doi: 10.1007/s10620-010-1202-9

103. Yamanashi $Y$, Takada $T$, Yamamoto $H$, Suzuki $H$. NPC1L1 facilitates sphingomyelin absorption and regulates diet-induced production of VLDL/LDL-associated S1P. Nutrients. (2020) 12:2641. doi: $10.3390 /$ nu12092641

104. Morifuji M, Higashi S, Oba C, Ichikawa S, Kawahata K, Yamaji $\mathrm{T}$, et al. Milk phospholipids enhance lymphatic absorption of dietary sphingomyelin in lymph-cannulated rats. Lipids. (2015) 50:987-96. doi: 10.1007/s11745-015-4054-4

105. Yamanashi Y, Takada T, Kurauchi R, Tanaka Y, Komine T, Suzuki H. Transporters for the intestinal absorption of cholesterol, vitamin e, and vitamin K. J Atheroscler Thromb. (2017) 24:347-59. doi: 10.5551/jat.RV16007

106. Conway V, Couture P, Richard C, Gauthier SF, Pouliot Y, Lamarche B. Impact of buttermilk consumption on plasma lipids and surrogate markers of cholesterol homeostasis in men and women. Nutr Metab Cardiovasc Dis. (2013) 23:1255-62. doi: 10.1016/j.numecd.2013.03.003

107. Ramprasath VR, Jones PJ, Buckley DD, Woollett LA, Heubi JE. Effect of dietary sphingomyelin on absorption and fractional synthetic rate of cholesterol and serum lipid profile in humans. Lipids Health Dis. (2013) 12:125. doi: 10.1186/1476-511X$12-125$

108. Keller S, Malarski A, Reuther C, Kertscher R, Kiehntopf M, Jahreis G. Milk phospholipid and plant sterol-dependent modulation of plasma lipids in healthy volunteers. Eur J Nutr. (2013) 52:1169-79. doi: 10.1007/s00394-012-0427-0

109. Ohlsson L, Burling H, Duan RD, Nilsson A. Effects of a sphingolipidenriched dairy formulation on postprandial lipid concentrations. Eur J Clin Nutr. (2010) 64:1344-9. doi: 10.1038/ejcn.2010.164

110. Rong X, Wang B, Dunham MM, Hedde PN, Wong JS, Gratton E, et al. Lpcat3-dependent production of arachidonoyl phospholipids is a key determinant of triglyceride secretion. Elife. (2015) 4:e06557. doi: 10.7554/eLife.06557

111. Li Z, Jiang H, Ding T, Lou C, Bui HH, Kuo MS, et al. Deficiency in lysophosphatidylcholine acyltransferase 3 reduces plasma levels of lipids by reducing lipid absorption in mice. Gastroenterology. (2015) 149:151929. doi: 10.1053/j.gastro.2015.07.012

112. Eliakim R, DeSchryver-Kecskemeti K, Nogee L, Stenson WF, Alpers DH. Isolation and characterization of a small intestinal surfactant-like particle containing alkaline phosphatase and other digestive enzymes. J Biol Chem. (1989) 264:20614-9. doi: 10.1016/S0021-9258(19)47107-X

113. Staggers JE, Frost SC, Wells MA. Studies on fat digestion, absorption, and transport in the suckling rat. III. Composition of bile and evidence for enterohepatic circulation of bile salts. J Lipid Res. (1982) 23:114351. doi: 10.1016/S0022-2275(20)38051-2

114. Tso P, Kendrick H, Balint JA, Simmonds WJ. Role of biliary phosphatidylcholine in the absorption and transport of dietary triolein in the rat. Gastroenterology. (1981) 80:60-5. doi: 10.1016/0016-5085(81)90191-8

115. Cui YJ, Cheng X, Weaver YM, Klaassen CD. Tissue distribution, genderdivergent expression, ontogeny, and chemical induction of multidrug resistance transporter genes (Mdr1a, Mdr1b, Mdr2) in mice. Drug Metab Dispos. (2009) 37:203-10. doi: 10.1124/dmd.108.023721

116. Nilsson A, Landin B, Jensen E, Akesson B. Absorption and lymphatic transport of exogenous and endogenous arachidonic and linoleic acid in the rat. Am J Physiol. (1987) $252(6 \mathrm{Pt}$. 1):G817-24. doi: 10.1152/ajpgi.1987.252.6.G817

117. Nilsson A, Melin T. Absorption and metabolism of orally fed arachidonic and linoleic acid in the rat. Am J Physiol. (1988) 255(5 Pt. 1):G6128. doi: 10.1152/ajpgi.1988.255.5.G612

118. Melin T, Qi C, Nilsson A. Bile but not chyle lipoprotein is an important source of arachidonic acid for the rat small intestine. Prostaglandins Leukot Essent Fatty Acids. (1996) 55:337-43. doi: 10.1016/S0952-3278(96)90040-X

119. Shindou H, Shimizu T. Acyl-CoA:lysophospholipid acyltransferases. J Biol Chem. (2009) 284:1-5. doi: 10.1074/jbc.R800046200
120. Hashidate-Yoshida T, Harayama T, Hishikawa D, Morimoto R, Hamano F, Tokuoka SM, et al. Fatty acid remodeling by LPCAT3 enriches arachidonate in phospholipid membranes and regulates triglyceride transport. Elife. (2015) 4:e06557. doi: 10.7554/eLife. 06328

121. Kennelly JP, van der Veen JN, Nelson RC, Leonard KA, Havinga R, Buteau $\mathrm{J}$, et al. Intestinal de novo phosphatidylcholine synthesis is required for dietary lipid absorption and metabolic homeostasis. J Lipid Res. (2018) 59:1695-708. doi: 10.1194/jlr.M087056

122. Eliakim R, Becich MJ, Green K, Alpers DH. Developmental expression of intestinal surfactant-like particles in rats. Am J Physiol. (1991) 261(2 Pt. 1):G269-79. doi: 10.1152/ajpgi.1991.261.2.G269

123. Tang WH, Wang Z, Levison BS, Koeth RA, Britt EB, Fu X, et al. Intestinal microbial metabolism of phosphatidylcholine and cardiovascular risk. N Engl J Med. (2013) 368:1575-84. doi: 10.1056/NEJMoa1109400

124. Cho CE, Aardema NDJ, Bunnell ML, Larson DP, Aguilar SS, Bergeson JR, et al. Effect of choline forms and gut microbiota composition on trimethylamine-N-Oxide response in healthy men. Nutrients. (2020) 12:2220. doi: $10.3390 /$ nu12082220

125. Bernhard W. Choline in cystic fibrosis: relations to pancreas insufficiency, enterohepatic cycle, PEMT and intestinal microbiota. Eur J Nutr. (2021) 60:1737-59. doi: 10.1007/s00394-020-02358-2

126. Hayashi H, Fujimoto K, Cardelli JA, Nutting DF, Bergstedt S, Tso P. Fat feeding increases size, but not number, of chylomicrons produced by small intestine. Am J Physiol. (1990) 259 (5 Pt. 1):G709-19. doi: 10.1152/ajpgi.1990.259.5.G709

127. Beil FU, Grundy SM. Studies on plasma lipoproteins during absorption of exogenous lecithin in man. J Lipid Res. (1980) 21:525-36. doi: 10.1016/S0022-2275(20)42223-0

128. Sundler R, Akesson B. Biosynthesis of phosphatidylethanolamines and phosphatidylcholines from ethanolamine and choline in rat liver. Biochem J. (1975) 146:309-15. doi: 10.1042/bj1460309

129. Garsin DA. Ethanolamine utilization in bacterial pathogens: roles and regulation. Nat Rev Microbiol. (2010) 8:290-5. doi: 10.1038/nrmicro2334

130. Zhou J, Xiong X, Wang KX, Zou LJ, Ji P, Yin YL. Ethanolamine enhances intestinal functions by altering gut microbiome and mucosal anti-stress capacity in weaned rats. Br J Nutr. (2018) 120:241-9. doi: 10.1017/S0007114518001101

131. Nagahashi M, Yamada A, Aoyagi T, Allegood J, Wakai T, Spiegel S, et al. Sphingosine-1-phosphate in the lymphatic fluid determined by novel methods. Heliyon. (2016) 2:e00219. doi: 10.1016/j.heliyon.2016.e00219

132. Duan RD, Nilsson A. Metabolism of sphingolipids in the gut and its relation to inflammation and cancer development. Prog Lipid Res. (2009) 48:6272. doi: $10.1016 /$ j.plipres.2008.04.003

133. Fujii A, Manabe $Y$, Aida $K$, Tsuduki T, Hirata T, Sugawara $T$. Selective absorption of dietary sphingoid bases from the intestine via efflux by P-glycoprotein in rats. J Nutr Sci Vitaminol. (2017) 63:4450. doi: $10.3177 /$ jnsv. 63.44

134. Ohta K, Hiraki S, Miyanabe M, Ueki T, Aida K, Manabe Y, et al. Appearance of intact molecules of dietary ceramides prepared from soy sauce lees and rice glucosylceramides in mouse plasma. J Agric Food Chem. (2021) 69:1003-10. doi: 10.1021/acs.jafc.0c07259

135. Zhou J, Xiong X, Wang K, Zou L, Lv D, Yin Y. Ethanolamine metabolism in the mammalian gastrointestinal tract: mechanisms, patterns, and importance. Curr Mol Med. (2017) 17:929. doi: 10.2174/1566524017666170331161715

136. van der Veen JN, Kennelly JP, Wan S, Vance JE, Vance DE, Jacobs RL. The critical role of phosphatidylcholine and phosphatidylethanolamine metabolism in health and disease. Biochim Biophys Acta. (2017) 1859:155872. doi: 10.1016/j.bbamem.2017.04.006

137. Setala NL, Holopainen JM, Metso J, Wiedmer SK, Yohannes G, Kinnunen PK, et al. Interfacial and lipid transfer properties of human phospholipid transfer protein: implications for the transfer mechanism of phospholipids. Biochemistry. (2007) 46:1312-9. doi: 10.1021/bi0621866

138. Shamburek RD, Zech LA, Cooper PS, Vandenbroek JM, Schwartz CC. Disappearance of two major phosphatidylcholines from plasma is predominantly via LCAT and hepatic lipase. Am J Physiol. (1996) 271 (6 Pt. 1):E1073-82. doi: 10.1152/ajpendo.1996.271.6.E1073 
139. Brindley DN. Hepatic secretion of lysophosphatidylcholine: a novel transport system for polyunsaturated fatty acids and choline. J Nutr Biochem. (1993) 4:442-9. doi: 10.1016/0955-2863(93)90061-Z

140. Nguyen LN, Ma D, Shui G, Wong P, Cazenave-Gassiot A, Zhang X, et al. $\mathrm{Mfsd} 2 \mathrm{a}$ is a transporter for the essential omega-3 fatty acid docosahexaenoic acid. Nature. (2014) 509:503-6. doi: 10.1038/nature13241

141. Prieto-Sanchez MT, Ruiz-Palacios M, Blanco-Carnero JE, Pagan A, Hellmuth $\mathrm{C}$, Uhl O, et al. Placental MFSD2a transporter is related to decreased DHA in cord blood of women with treated gestational diabetes. Clin Nutr. (2017) 36:513-21. doi: 10.1016/j.clnu.2016.01.014

142. Landin B, Nilsson A, Twu JS, Schotz MC. A role for hepatic lipase in chylomicron and high density lipoprotein phospholipid metabolism. J Lipid Res. (1984) 25:559-63. doi: 10.1016/S0022-2275(20)3 7768-3

143. van Haperen R, Samyn H, van Gent T, Zonneveld AJ, Moerland M, Grosveld F, et al. Novel roles of hepatic lipase and phospholipid transfer protein in VLDL as well as HDL metabolism. Biochim Biophys Acta. (2009) 1791:10316. doi: 10.1016/j.bbalip.2009.06.001

144. Zierenberg O, Grundy SM. Intestinal absorption of polyenephosphatidylcholine in man. J Lipid Res. (1982) 23:113642. doi: 10.1016/S0022-2275(20)38050-0

145. Subbaiah PV, Sowa JM, Davidson MH. Evidence for altered positional specificity of LCAT in vivo: studies with docosahexaenoic acid feeding in humans. J Lipid Res. (2004) 45:2245-51. doi: 10.1194/jlr.M400197-JLR200

146. Stein Y, Stein O. Metabolism of labeled lysolecithin, lysophosphatidyl ethanolamine and lecithin in the rat. Biochim Biophys Acta. (1966) 116:95107. doi: 10.1016/0005-2760(66)90095-6

147. Zhou L, Nilsson, A. Uptake of arachidonic acid from blood 2-lysophatidylcholine by extrahepatic tissues in vivo. An experimental study in the rat. J Nutr Biochem. (1997) 11:6416. doi: 10.1016/S0955-2863(97)00114-9

148. Freeman JJ, Choi RL, Jenden DJ. Plasma choline: its turnover and exchange with brain choline. J Neurochem. (1975) 24:72934. doi: 10.1111/j.1471-4159.1975.tb03856.x

149. Ennis EA, Blakely RD. Choline on the move: perspectives on the molecular physiology and pharmacology of the presynaptic choline transporter. $A d v$ Pharmacol. (2016) 76:175-213. doi: 10.1016/bs.apha.2016.03.001

150. Hedtke V, Bakovic M. Choline transport for phospholipid synthesis: an emerging role of choline transporter-like protein 1. Exp Biol Med. (2019) 244:655-62. doi: 10.1177/1535370219830997

151. Samodelov SL, Kullak-Ublick GA, Gai Z, Visentin M. Organic cation transporters in human physiology, pharmacology, and toxicology. Int J Mol Sci. (2020) 21:7890. doi: 10.3390/ijms21217890

152. Thies F, Pillon C, Moliere P, Lagarde M, Lecerf J. Preferential incorporation of sn-2 lysoPC DHA over unesterified DHA in the young rat brain. Am J Physiol. (1994) 267 (5 Pt. 2):R1273-9. doi: 10.1152/ajpregu.1994.267.5.R1273

153. Lemaitre-Delaunay D, Pachiaudi C, Laville M, Pousin J, Armstrong M, Lagarde M. Blood compartmental metabolism of docosahexaenoic acid (DHA) in humans after ingestion of a single dose of [(13)C]DHA in phosphatidylcholine. I Lipid Res. (1999) 40:1867-74. doi: 10.1016/S0022-2275(20)34903-8

154. Hachem M, Belkouch M, Lo Van A, Picq M, Bernoud-Hubac N, Lagarde M. Brain targeting with docosahexaenoic acid as a prospective therapy for neurodegenerative diseases and its passage across blood brain barrier. Biochimie. (2020) 170:203-11. doi: 10.1016/j.biochi.2020.01.013

155. Guemez-Gamboa A, Nguyen LN, Yang H, Zaki MS, Kara M, Ben-Omran T, et al. Inactivating mutations in MFSD2A, required for omega-3 fatty acid transport in brain, cause a lethal microcephaly syndrome. Nat Genet. (2015) 47:809-13. doi: 10.1038/ng.3311

156. Goss KCW, Goss VM, Townsend JP, Koster G, Clark HW, Postle AD. Postnatal adaptations of phosphatidylcholine metabolism in extremely preterm infants: implications for choline and PUFA metabolism. Am J Clin Nutr. (2020) 112:1438-47. doi: 10.1093/ajcn/nqaa207

157. Bernhard W, Poets CF, Franz AR. Choline and choline-related nutrients in regular and preterm infant growth. Eur J Nutr. (2019) 58:93145. doi: 10.1007/s00394-018-1834-7

158. Uhl O, Fleddermann M, Hellmuth C, Demmelmair H, Koletzko B. Phospholipid species in newborn and 4 month old infants after consumption of different formulas or breast milk. PLoS ONE. (2016) 11:e0162040. doi: 10.1371/journal.pone.0162040

159. Eisenberg S, Stein Y, Stein O. The role of placenta in lysolecithin metabolism in rats and mice. Biochim Biophys Acta. (1967) 137:11520. doi: 10.1016/0005-2760(67)90014-8

160. Sundler R, Akesson B. Regulation of phospholipid biosynthesis in isolated rat hepatocytes. Effect of different substrates. J Biol Chem. (1975) 250:335967. doi: 10.1016/S0021-9258(19)41523-8

161. Melin T, Qi C, Bengtsson-Olivecrona G, Akesson B, Nilsson A. Hydrolysis of chylomicron polyenoic fatty acid esters with lipoprotein lipase and hepatic lipase. Biochim Biophys Acta. (1991) 1075:259-66. doi: 10.1016/0304-4165(91)90274-K

162. Hjelte L, Strandvik B, Nilsson A. Metabolism of $[3 \mathrm{H}]$ arachidonic acid- and [14C]linoleic acid-labelled chylomicrons in essential fatty acid-deficient rats. Biochim Biophys Acta. (1990) 1044:10110. doi: 10.1016/0005-2760(90)90224-L

163. Norris GH, Jiang C, Ryan J, Porter CM, Blesso CN. Milk sphingomyelin improves lipid metabolism and alters gut microbiota in high fat diet-fed mice. J Nutr Biochem. (2016) 30:93-101. doi: 10.1016/j.jnutbio.2015.12.003

164. Desmarchelier C, Borel P, Lairon D, Maraninchi M, Valero R. Effect of nutrient and micronutrient intake on chylomicron production and postprandial lipemia. Nutrients. (2019) 11:1299. doi: 10.3390/nu11061299

165. Perez-Martinez P, Ordovas JM, Garcia-Rios A, Delgado-Lista J, DelgadoCasado N, Cruz-Teno C, et al. Consumption of diets with different type of fat influences triacylglycerols-rich lipoproteins particle number and size during the postprandial state. Nutr Metab Cardiovasc Dis. (2011) 21:3945. doi: 10.1016/j.numecd.2009.07.008

166. Mekki N, Charbonnier M, Borel P, Leonardi J, Juhel C, Portugal H, et al. Butter differs from olive oil and sunflower oil in its effects on postprandial lipemia and triacylglycerol-rich lipoproteins after single mixed meals in healthy young men. J Nutr. (2002) 132:3642-9. doi: 10.1093/jn/132.12.3642

167. Turgeon SL, Brisson G. The dairy matrix-Bioaccessibility and bioavailability of nutrients and physiological effects. J Dairy Sci. (2019) 103:6727-36. doi: 10.3168/jds.2019-17308

168. Lecomte M, Bourlieu C, Meugnier E, Penhoat A, Cheillan D, Pineau G, et al. Milk polar lipids affect in vitro digestive lipolysis and postprandial lipid metabolism in mice. J Nutr. (2015) 145:1770-7. doi: 10.3945/jn.115.212068

169. Rosqvist F, Smedman A, Lindmark-Mansson H, Paulsson M, Petrus $\mathrm{P}$, Straniero S, et al. Potential role of milk fat globule membrane in modulating plasma lipoproteins, gene expression, and cholesterol metabolism in humans: a randomized study. Am J Clin Nutr. (2015) 102:2030. doi: 10.3945/ajcn.115.107045

170. Meikle PJ, Barlow CK, Mellett NA, Mundra PA, Bonham MP, Larsen A, et al. Postprandial plasma phospholipids in men are influenced by the source of dietary fat. J Nutr. (2015) 145:2012-8. doi: 10.3945/jn.115.210104

171. Dubois C, Beaumier G, Juhel C, Armand M, Portugal H, Pauli AM, et al. Effects of graded amounts (0-50 g) of dietary fat on postprandial lipemia and lipoproteins in normolipidemic adults. Am J Clin Nutr. (1998) 67:318. doi: $10.1093 / \mathrm{ajcn} / 67.1 .31$

172. Moreno-Navarrete JM, Catalan V, Whyte L, Diaz-Arteaga A, VazquezMartinez R, Rotellar F, et al. The L-alpha-lysophosphatidylinositol/GPR55 system and its potential role in human obesity. Diabetes. (2012) 61:28191. doi: 10.2337/db11-0649

173. Nilsson A, Chen Q, Dahlman E. Metabolism of chylomicron phosphatidylinositol in the rat: fate in vivo and hydrolysis with lipoprotein lipase and hepatic lipase in vitro. J Lipid Res. (1994) 35:2151-60. doi: 10.1016/S0022-2275(20)39921-1

174. Meikle PJ, Wong G, Barlow CK, Weir JM, Greeve MA, MacIntosh GL, et al. Plasma lipid profiling shows similar associations with prediabetes and type 2 diabetes. PLoS ONE. (2013) 8:e74341. doi: 10.1371/journal.pone.0074341

175. Hansson P, Holven KB, Oyri LKL, Brekke HK, Gjevestad GO, Rehfeld JF, et al. Dairy products influence gut hormone secretion and appetite differently: a randomized controlled crossover trial. J Dairy Sci. (2020) 103:1100-9. doi: 10.3168/jds.2019-16863

176. Ulven SM, Holven KB, Gil A, Rangel-Huerta OD. Milk and dairy product consumption and inflammatory biomarkers: an updated systematic review of randomized clinical trials. Adv Nutr. (2019) 10:S239-50. doi: 10.1093/advances/nmy072 
177. Rundblad A, Holven KB, Oyri LKL, Hansson P, Ivan IH, Gjevestad GO, et al. Intake of fermented dairy products induces a less pro-inflammatory postprandial peripheral blood mononuclear cell gene expression response than non-fermented dairy products: a randomized controlled cross-over trial. Mol Nutr Food Res. (2020) 64:e2000319. doi: 10.1002/mnfr.202000319

178. Sprenger RR, Hermansson M, Neess D, Becciolini LS, Sorensen $\mathrm{SB}$, Fagerberg R, et al. Lipid molecular timeline profiling reveals diurnal crosstalk between the liver and circulation. Cell Rep. (2021) 34:108710. doi: $10.1016 /$ j.celrep.2021.108710

Conflict of Interest: The authors declare that the research was conducted in the absence of any commercial or financial relationships that could be construed as a potential conflict of interest.
Publisher's Note: All claims expressed in this article are solely those of the authors and do not necessarily represent those of their affiliated organizations, or those of the publisher, the editors and the reviewers. Any product that may be evaluated in this article, or claim that may be made by its manufacturer, is not guaranteed or endorsed by the publisher.

Copyright $\odot 2021$ Nilsson, Duan and Ohlsson. This is an open-access article distributed under the terms of the Creative Commons Attribution License (CC BY). The use, distribution or reproduction in other forums is permitted, provided the original author(s) and the copyright owner(s) are credited and that the original publication in this journal is cited, in accordance with accepted academic practice. No use, distribution or reproduction is permitted which does not comply with these terms. 